\title{
Giant fossil soft-shelled turtles of North America
}

\author{
Natasha S. Vitek
}

\begin{abstract}
Axestemys byssina, a large, potentially paedomorphic soft-shelled turtle (Trionychidae), and a number of other of giant trionychids were described over a century ago, but no rigorous analysis has been undertaken to investigate their relationships. These trionychids are unusual and are known from a broad temporal range spanning from the Cretaceous to the Eocene (70-46 m.y.a.). I examined all material previously assigned to Axestemys as well as previously undescribed material with traditional "Axestemys"like characteristics and provided a concept of Axestemys that is meaningful in both systematic and taxonomic contexts. Two new species are established. Axestemys byssina and Axestemys splendida comb. nov. are revised as a result of the description of new material, and Axestemys quinni is confirmed to be a member of Axestemys. Eugenichelys robertemryi Chkhikvadze, 2008 is synonymized with Axestemys byssina. Phylogenetic analysis and description of new material does not support the inclusion within the clade of "Axestemys" puercensis and Conchochelys admiribalis, previously hypothesized to belong to Axestemys. The taxon name 'Axestemys' is best defined phylogenetically as a stem-based clade rather than defined based on many of the characters traditionally ascribed to it, which are not consistently present throughout all species of Axestemys. All members of Axestemys reach a gigantic size that is today found only in a few tropical species of trionychid that independently evolved gigantism. The presence of Axestemys reflects both a warmer climate in the past in North America. Additionally, it reflects a high trionychid diversity and disparity comparable to those of Recent species confined to tropical climates today.
\end{abstract}

Natasha S. Vitek. Department of Geology and Geophysics, Yale University, 210 Whitney Avenue, P.O. Box 208109, New Haven, CT 06520, USA, nsvitek@utexas.edu

Keywords: new species; biodiversity; phylogenetics; Trionychidae; Axestemys

\section{INTRODUCTION}

Soft-shelled turtles (Trionychidae) are a clade of highly modified aquatic turtles whose bony shells are covered by a layer of leathery skin. They lack several features common to most other turtles, such as keratinous scutes, pygal bones, and an ossified bridge between the dorsal carapace and ventral plastron (Ernst and Barbour, 1989). Recent diversity is limited to 26 species distributed through North America, Africa, Asia, and the Indo-Austra- 
TABLE 1. Taxonomic history of North American species historically or currently considered a part of Axestemys. A dash indicates that the species was not mentioned in a given reference.

\begin{tabular}{|c|c|c|c|c|c|c|c|}
\hline $\begin{array}{c}\text { Cope, } \\
1872\end{array}$ & $\begin{array}{l}\text { Hay, } \\
1908\end{array}$ & $\begin{array}{c}\text { Schmidt, } \\
1945\end{array}$ & $\begin{array}{c}\text { Gaffney, } \\
1979\end{array}$ & $\begin{array}{c}\text { Gardner et al., } \\
1995\end{array}$ & $\begin{array}{c}\text { Chkhikvadze, } \\
2000\end{array}$ & $\begin{array}{c}\text { Hutchison } \\
\text { and } \\
\text { Holroyd, } \\
2003\end{array}$ & This study \\
\hline- & $\begin{array}{l}\text { Conchochelys } \\
\text { admiribalis }\end{array}$ & - & - & - & $\begin{array}{l}\text { Conchochelys } \\
\text { admiribalis }\end{array}$ & $\begin{array}{l}\text { Axestemys } \\
\text { admiribalis }\end{array}$ & $\begin{array}{l}\text { Conchochelys } \\
\text { admiribalis }\end{array}$ \\
\hline $\begin{array}{l}\text { Axestus } \\
\text { byssinus }\end{array}$ & $\begin{array}{l}\text { Axestemys } \\
\text { byssina }\end{array}$ & - & $\begin{array}{l}\text { Trionyx } \\
\text { byssinus }\end{array}$ & - & $\begin{array}{l}\text { Axestemys } \\
\text { byssina }\end{array}$ & $\begin{array}{l}\text { Axestemys } \\
\text { byssina }\end{array}$ & $\begin{array}{l}\text { Axestemys } \\
\text { byssina }\end{array}$ \\
\hline- & - & - & $\begin{array}{l}\text { Trionychidae } \\
\text { gen. indet. }\end{array}$ & - & - & $\begin{array}{l}\text { Axestemys } \\
\text { indet. }\end{array}$ & $\begin{array}{l}\text { Axestemys } \\
\text { cerevesia }\end{array}$ \\
\hline- & - & - & - & - & - & - & $\begin{array}{l}\text { Axestemys } \\
\text { montinsana }\end{array}$ \\
\hline- & $\begin{array}{l}\text { Aspideretes } \\
\text { puercensis }\end{array}$ & $\begin{array}{l}\text { Paleotrionyx } \\
\text { puercensis }\end{array}$ & $\begin{array}{l}\text { Trionyx } \\
\text { puercensis }\end{array}$ & - & $\begin{array}{l}\text { Paleotrionyx } \\
\text { puercensis }\end{array}$ & $\begin{array}{l}\text { Axestemys } \\
\text { puercensis }\end{array}$ & $\begin{array}{l}\text { "Trionyx" } \\
\text { puercensis }\end{array}$ \\
\hline- & - & $\begin{array}{l}\text { Paleotrionyx } \\
\text { quinni }\end{array}$ & Trionyx quinni & & $\begin{array}{l}\text { Paleotrionyx } \\
\text { quinni }\end{array}$ & $\begin{array}{l}\text { Axestemys } \\
\text { quinni }\end{array}$ & $\begin{array}{l}\text { Axestemys } \\
\text { quinni }\end{array}$ \\
\hline- & - & - & - & - & $\begin{array}{l}\text { Eugenichelys } \\
\text { roberte } \\
\text { mryi }\end{array}$ & - & $\begin{array}{l}\text { Axestemys } \\
\text { montinsana }\end{array}$ \\
\hline - & $\begin{array}{l}\text { Aspideretes } \\
\text { splendidus }\end{array}$ & - & - & $\begin{array}{l}\text { Aspideretoides } \\
\text { splendidus }\end{array}$ & $\begin{array}{l}\text { Eugenichelys } \\
\text { splendidus }\end{array}$ & - & $\begin{array}{l}\text { Axestemys } \\
\text { splendida }\end{array}$ \\
\hline
\end{tabular}

lian archipelago (Meylan, 1987; Ernst and Barbour, 1989; Engstrom et al., 2004).

The fossil record of trionychids extends at least as far back as the earliest Late Cretaceous in North America (Brinkman, 2003). However, the evolutionary history of Trionychidae within North America is still unclear, partly because many taxa were named more than one hundred years ago (e.g., Hay, 1908) based on fragmentary material with few or no characters considered diagnostic today (Joyce et al., 2009).

In particular, Axestemys byssina (Cope, 1872) - a large, potentially paedomorphic trionychid-and a number of similar taxa deserve further study. Because of the long rib ends, postnuchal fontanelles, and characteristically smooth plastron found in referred species, Axestemys was historically considered a group with a bizarre morphology within the already morphologically bizarre Trionychidae (Hay, 1908; Hutchison and Holroyd, 2003). The group presents an opportunity to explore potential influences on trionychid evolution that could produce giant species with potentially unusual morphological characters.

A summary of the taxonomic history given below is provided in Table 1. The type localities for the species discussed are shown in Figure 1. Edward Drinker Cope (1872) originally named the taxon 'Axestus byssinus' based on a single, large xiphiplastron and some fragmentary non-shell postcranial bones. Unlike the rugose, sculptured xiphiplastra of all other North American trionychids known at that time, the xiphiplastron was covered by a smooth, unsculptured callosity. Later, the generic name was changed to 'Axestemys' due to the fact that the name 'Axestus' was already in use for a group of beetles (Hay, 1899). In his review of the fossil turtles of North America, Hay (1908) also referred several other hypoplastral and carapace fragments to Axestemys byssina. In the process, he described new characters present in the taxon, including a relatively large - but not gigantic-estimated carapace length of $42 \mathrm{~cm}$, the presence of suprascapular fontanelles and a smooth hyoplastral-hypoplastral callosity similar to the smooth xiphiplastral callosity in the holotype specimen.

In subsequent decades other gigantic trionychids were described. Conchochelys admiribalis Hay, 1905, was named based on a single, gigantic skull. Although the skull was poorly preserved with few visible sutures, and although no shell material or additional skull material was available at the 


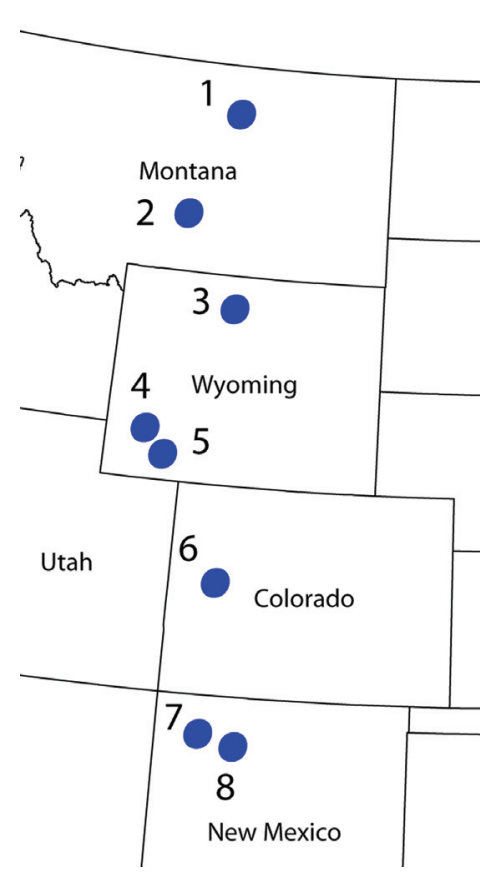

FIGURE 1. Map of type localities of the species of trionychids discussed in this manuscript. 1. Axestemys splendida (Hay, 1908), 2. Axestemys montinsana sp. nov., 3. Eugenichelys robertemryi Chkhikvadze, 2008, 4. Axestemys cerevesia sp. nov., 5. Axestemys byssina (Cope, 1872), 6. Axestemys quinni (Schmidt, 1945), 7. Conchochelys admiribalis Hay, 1905, 8. "Axestemys" puercensis (Hay, 1908).

time, the generic name Conchochelys was established for the specimen based on the breadth of the skull, the narrow pterygoid region, and shortened squamosal processes.

The name 'Paleotrionyx' was established based on the new taxon Paleotrionyx quinni Schmidt, 1945 (Schmidt, 1945). A second species, Aspideretes puercensis Hay, 1908, was also referred to Paleotrionyx on the basis of large suprascapular fontanelles that separated the nuchal from the first costal. Another gigantic fossil trionychid with similarly large suprascapular fontanelles, as well as a smooth border on the callosity covering the carapace was later described (Gaffney, 1979). The author noted the similarities of that specimen to Axestemys and Paleotrionyx, but refrained from giving the specimen a name or making any taxonomic revisions.

Meanwhile, other scientists debated the systematics of Axestemys within Trionychidae. Some suggested that the shell-only Axestemys and Paleotrionyx and the skull-only taxon Conchochelys were synonymous within Trionychidae (de Broin, 1977; Kordikova, 1994). Another researcher con- sidered Axestemys a separate taxon from Paleotrionyx and placed Axestemys as a subgenus of Rafetus (Chkhikhvadze, 2000). The latter arrangement required the establishment of the tribe Rafetini and two subdivisions. The first subdivision was Rafetus (Rafetus), which included $R$. euphraticus Daudin, 1802, and R. swinhoei Gray, 1873, the two extant species traditionally referred to Rafetus. The second subdivision was Rafetus (Axestemys), which included several fossil North American trionychid species, including Axestemys byssina.

The systematics of Axestemys were formally addressed when Hutchison and Holroyd (2003) described new, fragmentary skull and shell material from Colorado. On the basis of the new material they synonymized Paleotrionyx puercensis and Conchochelys admiribalis. That material in addition to Gaffney's (1979) unnamed turtle provided the basis for synonymizing Axestemys and Paleotrionyx (and, therefore, Conchochelys). According to their analysis, Axestemys included the three species Axestemys byssina, Axestemys admiribalis, and Axestemys quinni, plus Gaffney's unnamed turtle. Their study did not support the placement of Axestemys within Rafetus. They suggested that "general paedomorphy of the shell" (Hutchison and Holroyd, 2003, p.134) was an apomorphy for Axestemys.

Newly discovered material makes possible a re-evaluation and phylogenetic analysis of Axestemys. The purpose of this study is to use all material previously assigned to Axestemys in the literature as well as previously undescribed material with traditional "Axestemys"-like characteristics to develop a concept of Axestemys that is meaningful in both taxonomic and systematic contexts. I include descriptions of new material attributable to Axestemys byssina and Axestemys splendida nov. comb., and establish two new taxa. In addition, the phylogenetic relationships within Axestemys and of Axestemys among extinct and extant Trionychidae are investigated for the first time and used to test the hypothesis that Axestemys is a monophyletic clade of giant fossil trionychids.

There are a number of Eurasian specimens that previously were referred to Paleotrionyx and/or Axestemys (de Broin, 1977; Kordikova, 1994), but are not addressed here. I focus only on potential North American representatives of Axestemys. Hopefully a clearer picture of North American taxa will provide insight for future studies of Eurasian trionychids.

Terminology for the skull follows Gaffney (1972); that for the shell follows Zangerl (1969). 
Institutional acronyms are as follows: $\mathrm{AMNH}=$ American Museum of Natural History, New York, New York; DMNH = Denver Museum of Nature and Science, Denver, Colorado; $\mathrm{FMNH}=$ Field Museum of Natural History, Chicago, Illinois; MRF = Marmarth Research Foundation, Marmarth, North Dakota; PTRM = Pioneer Trails Regional Museum, Bowman, North Dakota; UCM = University of Colorado Museum, Boulder, Colorado; UMMP = University of Michigan Museum of Paleontology, Ann Arbor, Michigan; USNM = National Museum of Natural History, Washington, D.C., UW = University of Wyoming, Laramie, Wyoming; YPM = Yale Peabody Museum, New Haven, Connecticut.

\section{MATERIALS AND METHODS}

A morphological dataset was used to conduct a phylogenetic analysis. Morphological data were reproduced from a combination of matrices published by Vitek (2011) and Joyce and Lyson (2011). The former is a slight revision of the extraction of Joyce et al. (2009) of characters from an earlier matrix of osteological characters of extant trionychids (Meylan, 1987). The second includes eight additional characters added to Joyce et al's. (2009) matrix.

As a result of the conclusions of Vitek (2011), the scorings for specimens and synonyms of Oliveremys uintaensis were combined into a single taxon and scored as such. The scoring for the plastomenid taxa Gilmoremys lancensis, Hutchemys arctochelys, Hutchemys rememdium, Hutchemys sterea, Hutchemys tetanetron, and Plastomenus thomasii (Joyce et al., 2009; Joyce and Lyson, 2011) as well as the trionychines Aspideretoides foveatus, Axestemys splendida, and "Trionyx" egregius (Gardner et al., 1995; Vitek, 2011) were included from previous analyses. For the purpose of this study, species historically considered part of Axestemys or displaying "Axestemys"-like characters were scored and added to the matrix. Those species are: Axestemys byssina, Axestemys cerevisia, Axestemys montinsana, Axestemys quinni, "Axestemys" puercensis, and Aspideretoides allani. Aspideretoides allani was scored based on the scoring of Gardner (1992) and the description of Gardner et al. (1995). Four new characters were added to the matrix in order to help resolve relationships among potential taxa of Axestemys. A list of characters used in the analysis is provided by Appendix 1. The taxon/character matrix used in the analysis is provided by Appendix 2. All specimens used in this analysis and for comparative purposes are listed in Appendix 3.

The parsimony analysis was conducted using

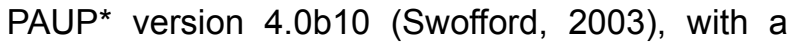
strict consensus tree (Figure 2.1) and an Adams consensus tree generated from heuristic search with tree bisection and reconnection (TBR) branchswapping and 100,000 replicates. All characters were run unordered, unweighted, and with no topological constraints. Minimum branch lengths were set to collapse. Polarity assessments were based on Meylan's (1987) analysis.

Because the initial analysis generated 315 most-parsimonious trees with poor resolution among Trionychinae, an exclusion experiment was performed to investigate possible sources of irresolution. After the initial parsimony analysis, one taxon was deleted based on its unresolved, basal position in the Adams consensus tree (see Phylogenetic Analysis in Results for further detail). Parsimony analysis was conducted based on that edited tree, with results checked against the previously recovered strict consensus tree to make sure that removing the taxon had not altered relationships originally recovered by the complete dataset. This process of removing a single taxon and re-performing the analysis was repeated until parsimony analysis recovered only a single tree (Figure 2.2).

Support for each node in the single tree recovered from the pruned data set was calculated using a bootstrap analysis with 1,000 bootstrap replicates and 100 random sequence addition replicates. Due to computational limitations, each bootstrap replicate was limited to a maximum of 1,000 most parsimonious trees. Strong support, that is bootstrap frequencies greater than $70 \%$, is shown in Figure 2.2.

\section{SYSTEMATIC PALEONTOLOGY}

TESTUDINES Batsch, 1788

CRYPTODIRA Cope, 1868

TRIONYCHIDAE Gray, 1825

TRIONYCHINAE Gray, 1825

AXESTEMYS (Hay, 1899) (converted clade name)

1872 Axestus Cope p. 462.

Type Species

Axestemys byssina Cope, 1872 USNM 4089.

\section{Included Species}

Axestemys cerevisia sp. nov., Axestemys montinsana sp. nov., Axestemys quinni (Schmidt, 1945), Axestemys splendida comb. nov. (Hay, 1908). 


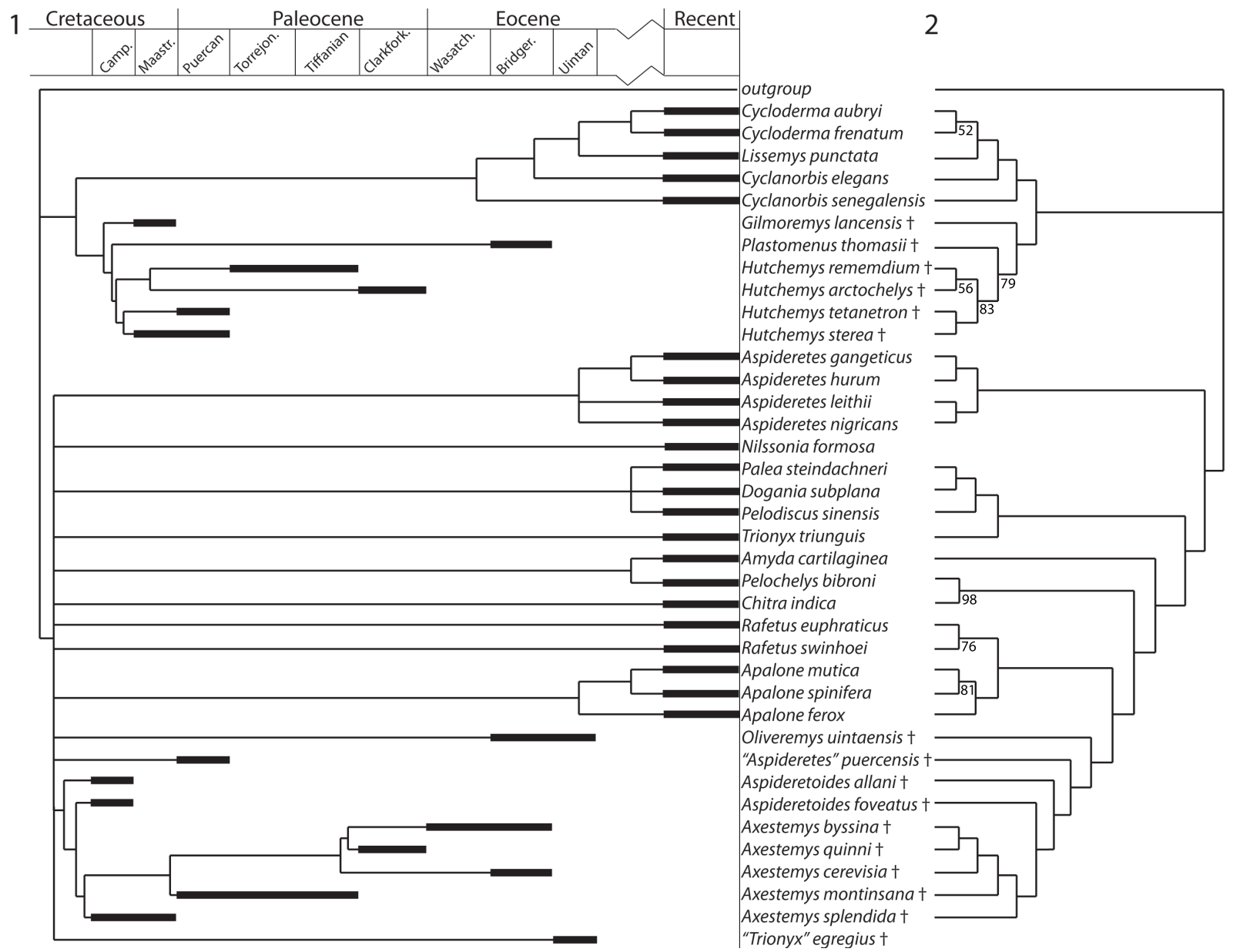

FIGURE 2. Most parsimonious trees resulting from analysis of fossil and recent Trionychidae based on morphological data. Axestemys is designated in black. Daggers indicate extinct species. Thick black lines represent the stratigraphic ranges of taxa. 1, The strict consensus tree topology of 315 most parsimonious trees, 288 steps, $\mathrm{Cl}=0.4063, \mathrm{RI}=$ 0.6183. 2, The single most parsimonious tree topology resulting from the experimental deletion of two taxa, Nilssonia formosa and the fossil "Trionyx" egregius, 283 steps, $\mathrm{Cl}=0.4134, \mathrm{RI}=0.6175$. Numbers to the lower right of nodes are bootstrap support values from 1000 bootstrap replicates. Abbreviations: Camp. = Campanian, Maastr. = Maastrichtian, Torrejon. $=$ Torrejonian, Clarkfork. = Clarkforkian, Wasatch. = Wasatchian, Bridger. = Bridgerian.

\section{Definition}

Axastemys is defined as the most inclusive clade containing the type species Axestemys byssina Cope, 1872 but excluding Aspideretoides foveatus (Leidy, 1856) as well as Apalone spinifera (Le Sueur, 1827), Aspideretes gangeticus (Cuvier, 1825), Rafetus euphraticus (Daudin, 1802), Trionyx triunguis (Forskål, 1775), Cyclanorbis senegalensis (Duméril and Bibron, 1835), Plastomenus thomasii (Cope, 1872), Chitra indica (Gray, 1831), and Pelodiscus sinensis (Wiegmann, 1835)

\section{Reference Phylogeny}

Figure 2.

\section{Diagnostic Apomorphies}

Axestemys can be diagnosed as a clade of trionychids with a carapace length $60 \mathrm{~cm}$ or longer.

\section{Comments}

Axestemys can be diagnosed as a member of Trionychinae sensu Meylan, 1987 by the presence of a nuchal at least four times wider than long, a short plastral bridge, dorsal edge of apertura narium externa weakly emarginated, and absence of posterior costiform processes on the nuchal, peripherals, and depression on the eighth costals for articulation of the ilia. Among other giant trionychids, Axestemys can be differentiated from Rafetus swinhoei by the presence of four plastral callosities on the plastron, from Chitra spp. by the 

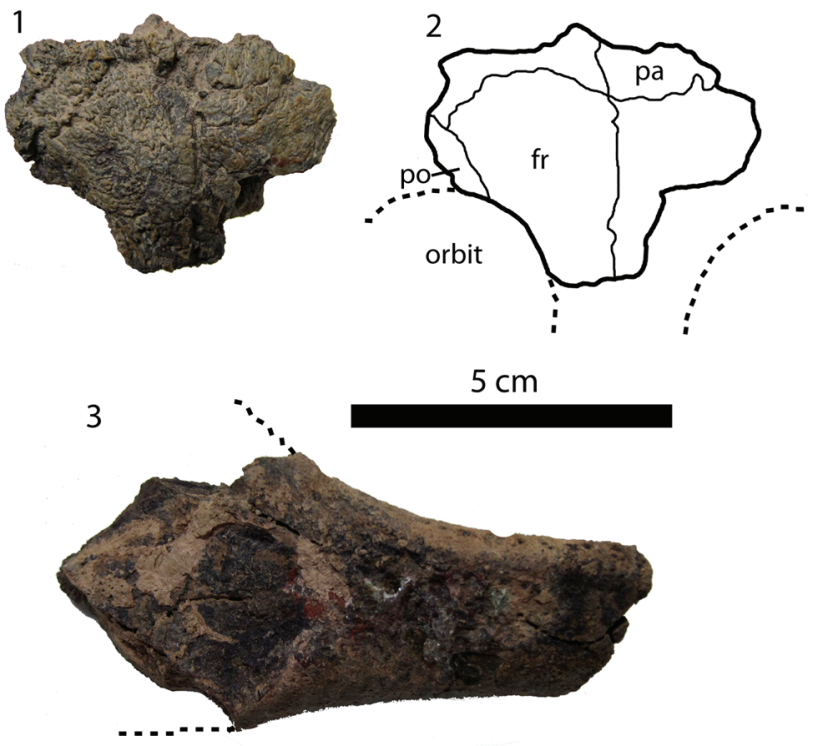

FIGURE 3. USNM 12589, skull fragments of Axestemys byssina from the Eocene Wasatch Formation of Wyoming. 1, Photograph and 2, illustration of skull roof fragment. 3, dentary fragment. Abbreviations: $f r=$ frontal, pa $=$ parietal, po $=$ postorbital.

position of the first thoracic vertebra in the middle of the nuchal, from Pelochelys spp. and Chitra spp. by a nuchal at least for times wider than long, and from "Trionyx" kansaiensis Vitek and Danilov, 2010 by the presence of a convex anterior carapace margin. Axestemys spp. can be differentiated from other Cretaceous-Eocene trionychids by their large size, by the presence of a preneural and a single lateral hyoplastral process, by the presence of 7 or 8 neurals (not including the preneural), by a lack of significant midline contact between the hyoplastra and hypoplastra and xiphiplastra, and variably by a smooth external surface on the plastron and/or lateral margin of the carapace.

Axestemys byssina Cope, 1872

1872 Axestus byssinus Cope, p. 462.

2008 Eugenichelys robertemryi Chkhikvadze, p. 90, fig. 7 .

Figures 3, 4, 5, 6, 7.9-10.

\section{Type Specimen}

USNM 4089, xiphiplastron, cervical vertebra, isolated ilium, several fragmentary appendicular elements.

\section{Horizon and Type Locality}

Black's Fork of Green River, (Bridgerian) Bridger Formation, Wyoming, USA.

\section{Referred Material}

USNM 12589, type specimen of Eugenichelys robertemryi, skull fragments, partial left dentary, left hyoplastron, right hypoplastron, left and right xiphiplastron; South Elk Creek, Big Horn County, Wyoming, USA; Wasatch Formation, Eocene (Wasatchian).

USNM 16174, fragmentary carapace, left and right hyoplastra and hypoplastra, partial epiplastron; East side of Elk Creek, Big Horn County, Wyoming, USA; Wasatch Formation, Eocene (Wasatchian).

AMNH 1034, partial medial hypoplastron; Upper Green River, Wyoming, USA; Bridger Formation, Eocene (Bridgerian).

AMNH 1046, partial medial hypoplastron, partial nuchal, partial costal 1, costal fragments; Wyoming, USA; Bridger Formation, Eocene (Bridgerian).

\section{Distribution}

Wasatch Formation (Wasatchian), Bridger Formation (Bridgerian) of Wyoming.

\section{Differential Diagnosis}

Axestemys byssina is diagnosed as a member of Axestemys by a maximum carapace length of at least $60 \mathrm{~cm}$, sculpturing on the skull roof, and a single lateral hyoplastral process. Axestemys byssina 


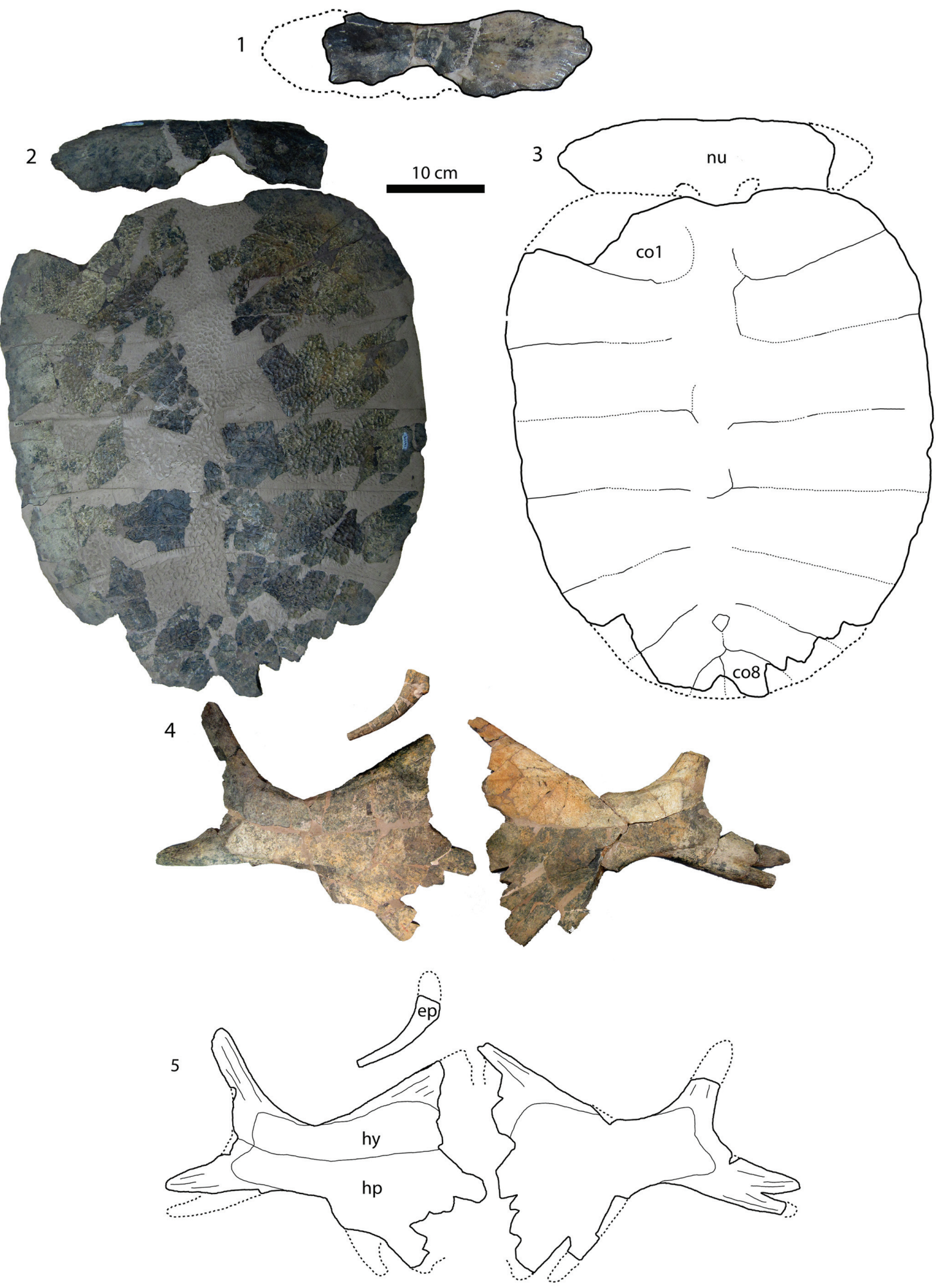

FIGURE 4. USNM 16174, carapace and plastron of Axestemys byssina from the Eocene Wasatch Formation of Wyoming. 1, Photograph of nuchal in visceral view. 2, Photograph and 3, illustration of carapace in external view. 4, Photograph and E, illustration of plastron. Abbreviations: $c 0=$ costal, $\mathrm{ep}=$ epiplastron, $\mathrm{hp}=$ hypoplastron, hy = hyoplastron, nu = nuchal. 


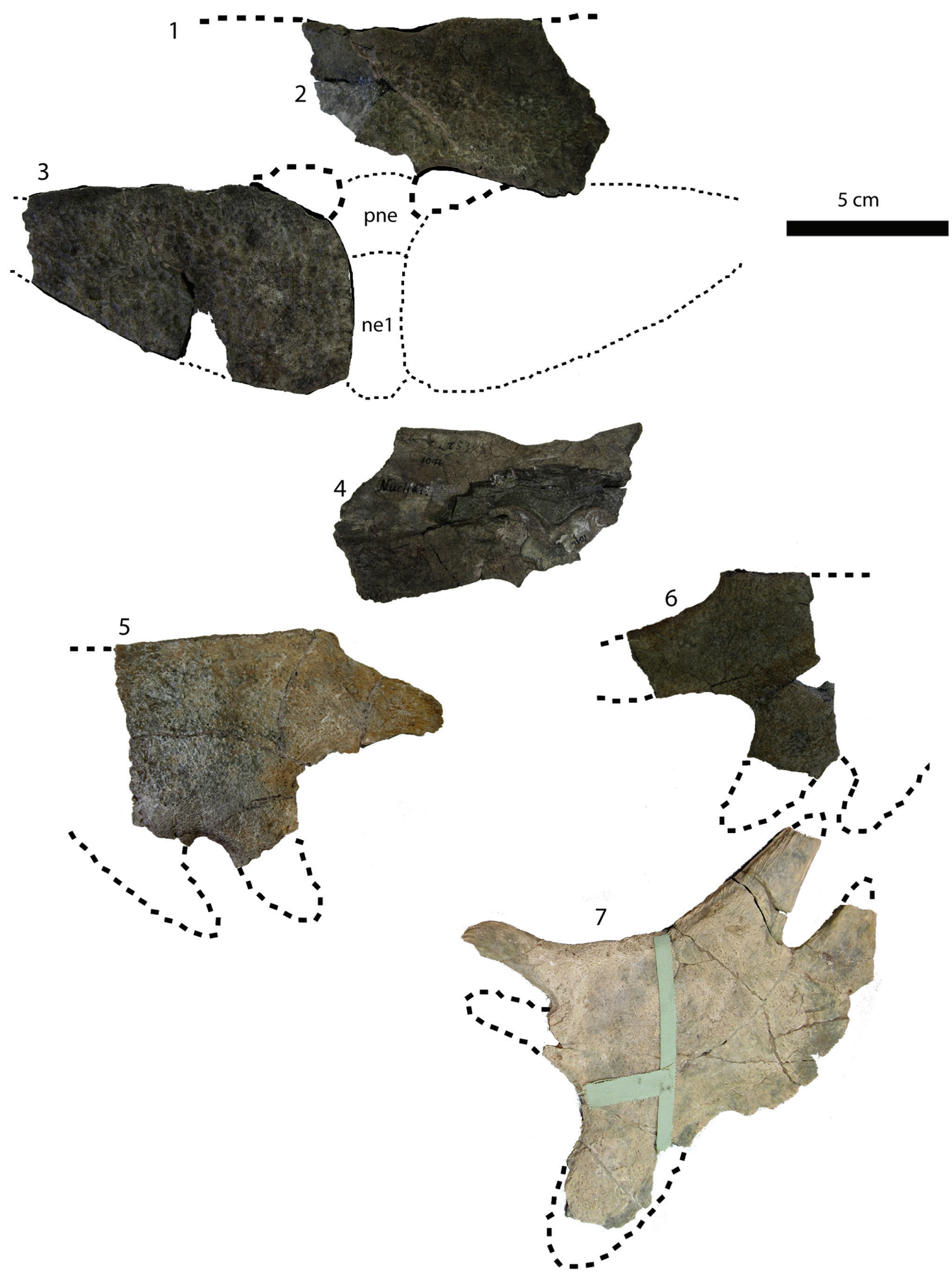

FIGURE 5. Photograph of Axestemys byssina material described by Hay (1908). 1, reconstruction of nuchal region. AMNH 1046, 2, partial nuchal in exterior view, 3, costal 1, 4, partial nuchal in visceral view. 5, AMNH 1034, partial hypoplastron from the Eocene Bridger Formation of Wyoming. 6. AMNH 1046, partial hypoplastron. 7, USNM 4089, holotype xiphiplastron from the Eocene Bridger Formation of Wyoming. Abbreviations: ne = neural, pne = preneural. 

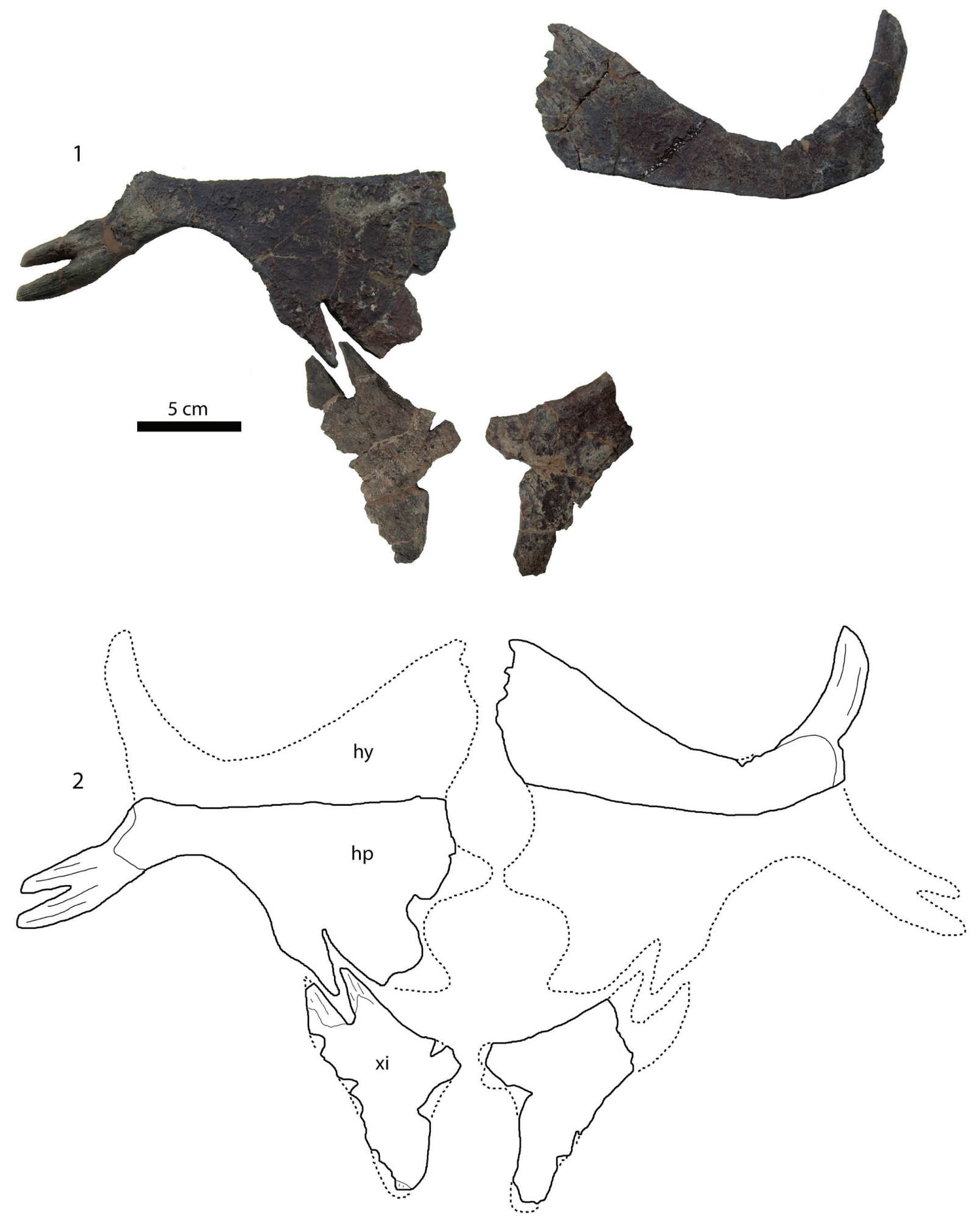

FIGURE 6. USNM 12589, plastron of Axestemys byssina from the Eocene Wasatch Formation of Wyoming. USNM 12589 is also the type specimen of Eugenichelys robertemryi, a junior synonym of Axestemys byssina, 1, photograph and 2, illustration. Abbreviations: $\mathrm{hp}=$ hypoplastron, hy = hyoplastron, $\mathrm{xi}=$ xiphiplastron. 


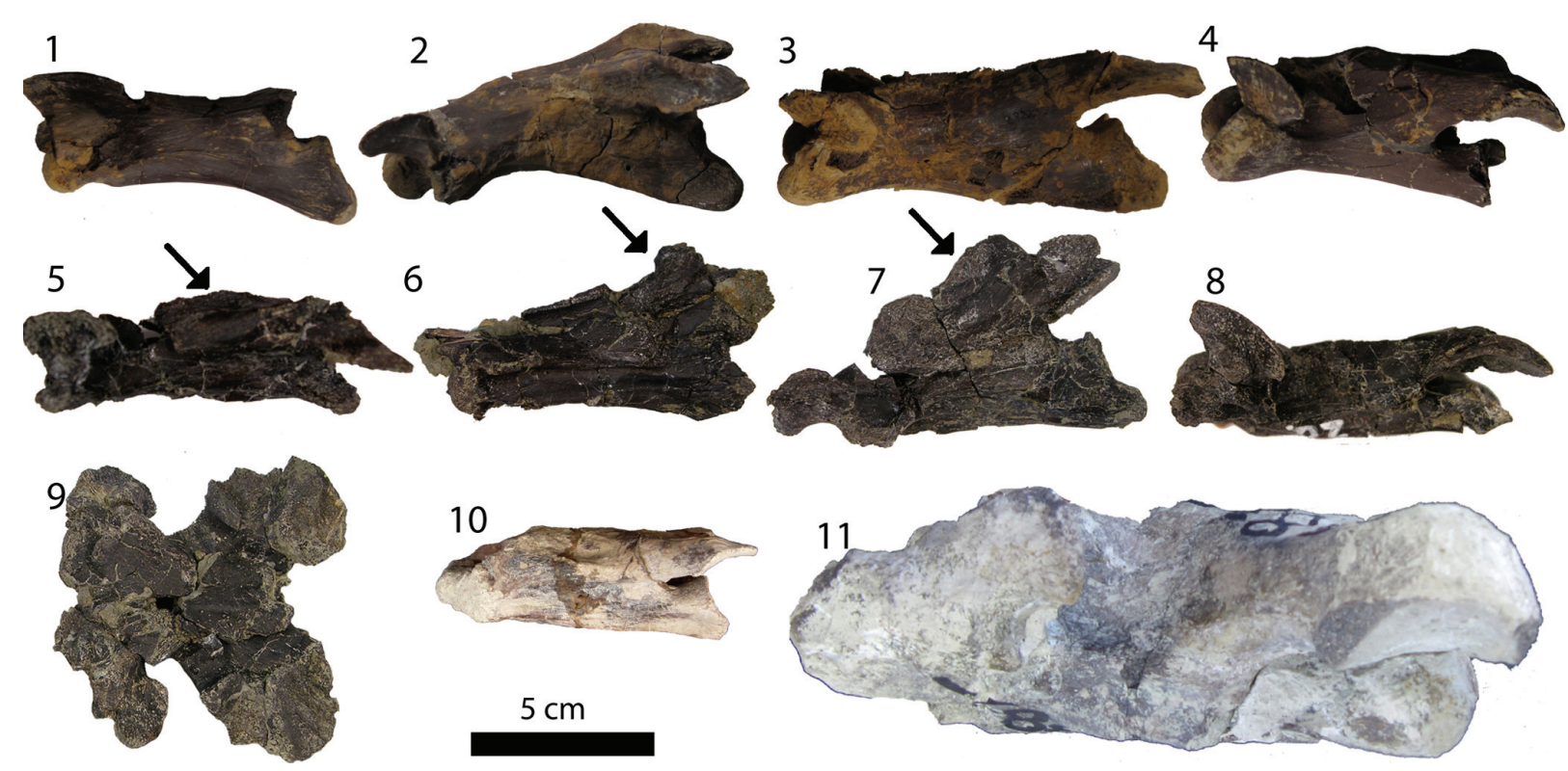

FIGURE 7. Cervical vertebrae of Axestemys. Lateral view of Axestemys montinsana from the Paleocene Fort Union Formation of North Dakota, order unknown, 1, PTRM 5350.22, 2, PTRM 5350.30, 3, PTRM 5350.108, 4, PTRM 5350.21, seventh cervical vertebra. UMMP 27029, Axestemys montinsana from the Paleocene Melville Formation of Montana, 5-7, cervical vertebrae in lateral view, order unknown, 8, seventh cervical vertebra in lateral view, 9, eighth cervical vertebra in ventral view, 10, seventh cervical vertebra in lateral view of Axestemys byssina from the Eocene Bridger Formation, 11, seventh cervical vertebra in lateral view of Axestemys cerevisia from the Eocene Bridger Formation. Arrows point to dorsal processes.

shares with Axestemys quinni the synapomorphy of highly reduced eighth costals. It can be differentiated from other member of Axestemys by a unique combination of suprascapular fontanelles, suture between lateral edge of nuchal and first costals, smooth hyoplastral-hypoplastral and xiphiplastral callosities, and wide, smooth border around carapacial callosity.

\section{Description of New Material}

Skull. Figure 3. A small piece of the skull roof and the margin of the orbit are preserved. The fragment contains parts of the frontals, parietals, and right postorbital. The surface is covered with a sculpture pattern of densely packed ridges, similar to the skull surface of Axestemys montinsana (UMMP 27029). Unlike Plastomenus thomasii, the parietals do not contribute to the margin of the orbit on the skull surface between the postorbital and the frontal, nor is the parietal contact with the orbit extended anteriorly (as described by Joyce and Lyson, 2011). In addition, the fragment comes from a large skull, with an orbit at least $28 \mathrm{~mm}$ in diameter.

Lower Jaw. Figure 3. The dentary fragment is massive and resembles the anterior portion of the dentary of both Axestemys montinsana and Axestemys splendida. The triturating surface is covered by matrix, but is wide and forms a lip in lateral view by extending beyond the anterior margin of the dentary.

Carapace. Figures 4, 5. The carapace of USNM 16174 , when complete with the nuchal attached, was about $60 \mathrm{~cm}$ long at the midline. Only one neural can be distinguished: a reduced, irregularly shaped neural at the end of the neural series. Given its placement, it is likely neural 7 . The anterior margin of the carapace is broadly convex, and the lateral margins are straight. The posterior margin of the carapace has a steeply concave notch at the midline. The carapace itself is oval-shaped. The costals and neurals are fully covered in a callosity. The callosity only covers the posteromedial part of the nuchal. The callosity itself consists of an outer unsculptured band $24 \mathrm{~mm}$ wide and a medial sculptured area. The sculpturing pattern consists of large, subcircular, flat pits surrounded by thin, uneven ridges, with several areas where the ridges separate into short rows or larger, irregular shapes. Sculpturing on carapace fragments of AMNH 1046 is identical, including the unsculptured margin visible on at least one lateral costal fragment. 
Nuchal. The reconstructed nuchal based on USNM 16174 is about four times wider than long. Both partial nuchals in USNM 16174 and AMNH 1046 lack a posterior costiform process. Contact with the thoracic vertebra is in the middle of the nuchal. Although both nuchals are incomplete, each preserves a smooth section of the posteromedial margin, indicating an area of the margin not sutured to the first costal and therefore the presence of suprascapular fontanelles. The anteromedial margin of the partial costal 1 in AMNH 1046 also has a matching area for such fontanelles. The fontanelles are relatively small, and do not extend to the first costal rib as do the fontanelles in Axestemys cerevisia, "Axestemys" puercensis, and Axestemys quinni.

Costals. Eight pairs of costals are present, with the eighth pair reduced. All of the rib ends are missing, and it is unclear how far they extended from the carapace margin. The edges of the costals, where complete, are rounded. The seventh and eighth costals probably made up the posterior margin of the carapace, although that margin is fragmented. Due to this fragmentation, the width:length ratio of the eighth costals is unclear. In USNM 16174 and AMNH 1046, the lateral margin of the first costal is just over half the size of the medial margin, but the lateral margin is not as radically constricted as in Gilmoremy lancensis.

Plastron. Figures 4-6. AMNH 1046, AMNH 1034, USNM 4089, USNM 12589, and USNM 16174 collectively preserve multiple xiphiplastra, hyoplastron and hypoplastra, and a single partial epiplastron. No entoplastron has been found in these specimens. The plastra as they are preserved have four unsculptured callosities: one on each hyoplastron and hypoplastron and one on each xiphiplastron. The unsculptured callosities can be differentiated from bone by a smooth surface with occasional cross-hatching, described by Hay as "textile-like fibers of bony tissue" (Hay, 1908, p. 509) and compared to "woven linen" by Cope (1872, p. 462).

Epiplastron. The fragment of the epiplastron in USNM 16174 preserves just enough of the bone to indicate that it was j-shaped in Meylan's (1987) terminology.

Hyoplastron and Hypoplastron. The callosity covers much of the medial part of the hyoplastron and hypoplastron, including most of the medial processes, but does not extend as far as the lateral margin of the hyoplastron and hypoplastron. The lateral processes are left entirely bare. The hyoplastral-hypoplastral bridge is short, about one-fifth the maximum hypoplastral width. Where the medial margin of the hyoplastron and hypoplastron is complete, there is no evidence for midline contact, nor is there an anterior hyoplastral shoulder for extensive contact with the entoplastron, unlike plastomenids. The hyoplastron has a single lateral process and several small hyoplastral processes. The exact number of processes on each specimen is unclear, although the hyoplastron in USNM 12589 has at least three. The hypoplastron has two lateral processes. In smaller specimens such as AMNH 1046 and 1034, the hypoplastron has a single large anteromedial process, followed by a large gap and two posteromedial processes that contact the xiphiplastron. The medial margins of USNM 12589 and USNM 16174 are too fragmentary to be sure what kind of pattern the medial hypoplastral processes had, but a broken anteromedial process on the right hypoplastron of USNM 16174 indicates that the pattern seen in smaller specimens was probably conserved in larger specimens.

Xiphiplastron. The xiphiplastra of Axestemys byssina are not as narrow as the xiphiplastra of Oliveremys uintaensis, another Eocene trionychid with unsculptured xiphiplastra. The width across the narrowest part of the body of all xiphiplastra of Axestemys byssina is at least one-third the length of the xiphiplastra along the lateral edge, whereas the width across all the xiphiplastra of Oliveremys uintaensis is no more than one-fourth of the length. However, the overall shape of the xiphiplastra of Axestemys byssina is also not as widely triangular as those in Axestemys montinsana. Rather, the xiphiplastra are intermediate, still roughly triangular in shape but more elongated, with an emargination along the lateral edge of the xiphiplastra that becomes less pronounced as a callosity grows to cover it. In addition to covering the lateral emargination, in larger, presumably older, individuals the callosity also grows to cover most of the processes on the xiphiplastron. In the xiphi-hypoplastral contact, the xiphiplastron is lateral-most. The xiphiplastra were reconstructed (Hay, 1908) as meeting at the midline via two anteromedial processes, such as the kind reconstructed in the holotype (Figure 5.7), but there is no suture or other evidence to suggest extensive midline contact.

Non-shell postcrania. Figure 7.10. A single cervical vertebra is preserved as part of the type specimen. It was referred to as the seventh (Hay, 1908). Unlike Axestemys montinsana and some other large trionychids (Meylan, 1987), Axestemys bys- 
sina lacks dorsal processes on the seventh cervical vertebra.

\section{Remarks}

In addition to describing Axestemys byssina based on USNM 4089, Hay (1908) referred the partial medial hypoplastron AMNH 1034 (Figure 5.5) to Axestemys byssina on the basis of its mention by Cope (1884) and the fact that both USNM 4089 and $\mathrm{AMNH} 1034$ are covered by an entirely unsculptured callosity. This character was also the basis for Hay's referral of the shell fragmentsincluding a partial hypoplastron-of AMNH 1046 (Figures 5.2-4, 6) to Axestemys and tentatively to Axestemys byssina (Hay, 1908). None of these three specimens were found at the same site. Furthermore, the two referred specimens have no xiphiplastra and therefore no characters that overlap with the holotype.

However, the more complete material of USNM 12589 and USNM 16174 supports Hay's (1908) conclusion that there is single taxon present in the Eocene, which has the same characters attributed to various specimens of Axestemys byssina and which is different from both Axestemys cerevisia, an Eocene taxon with callosified but unsculptured hyoplastra and hypoplastra, and Oliveremys uintaensis, another Eocene taxon with callosified but unsculptured xiphiplastra. In addition to the characters described above, it is likely that Axestemys byssina also differs from Oliveremys uintaensis in the presence of a preneural, which Oliveremys uintaensis lacks. It was assumed that Axestemys byssina lacked a preneural (Hay, 1908), and none of the referred material preserves either a preneural or a first neural that would clarify whether or not that element is present. Nevertheless, a preneural is present in all more basal species of Axestemys. In the absence of direct evidence, it is more parsimonious to infer that Axestemys byssina also had a preneural. Further remarks concerning Eugenichelys robertemryi, a junior synonym of Axestemys byssina, can be found in the Systematics section of the Results.

Axestemys splendida (Hay 1908) comb. nov.

1908 Aspideretes splendidus Hay, p. 490.

1995 Aspideretoides splenididus Gardner et al., p. 636 , figs. 2B, 2C, 3B-3D, 4B, 4C, 6.

Figures 7, 8, 9, 10, 11.

\section{Type Specimen}

AMNH 3952, partial carapace.

\section{Horizon and Type Locality}

Judith River Group (Judithian), Judith River Basin, Montana.

\section{Referred Material}

MRF 266, skull; Turtle Ridge Locality, Slope County, North Dakota, USA; Hell Creek Formation, Late Cretaceous (Maastrichtian).

MRF 666, lower jaw; MRF 834-835, partial carapace and complete right hyoplastron and hypoplastron; MRF 849, partial carapace and dentary; MRF 700, preneural; MRF 631, costal 1; MRF 654, 676, costal; MRF 567, 675, 678 hyoplastron; MRF 699, partial pectoral girdle; MRF 586, MRF 661, femur; all specimens from Big Turtle Cove Locality, Slope County, North Dakota, USA; Hell Creek Formation, Late Cretaceous (Maastrichtian). MRF 567, MRF 631, MRF 654, MRF 675, MRF 676, MRF 699-700, and MRF 849 probably all belong to one individual. MRF 586, 661, 666, 678, and 834-835 probably all belong to a second individual.

\section{Distribution}

Judith River Group (Judithian), Alberta and Montana; Hell Creek Formation (Maastrichtian), North Dakota.

\section{Revised Differential Diagnosis}

Characters that help differentiate Axestemys splendida from other fossil trionychids but are not unique to this taxon include presence of a preneural, a single lateral hyoplastral process, and a maximum known carapace length at least $690 \mathrm{~mm}$. Other characters taken from Gardner et al. (1995, p. 636) include "dorsomedian carapacial sculpture of larger individuals consists of high, narrow ridges bordering wavy, flat-bottomed, reticulate lacunae and (or) inosculating troughs; hypoplastral inguinal border thick; medial edge of xiphiplastral callosities in broad, unsutured medial contact in adults. Further differs from Aspideretoides foveatus as follows: length of epiplastral projections about onequarter maximum hypoplastral width; epiplastral anterior projection wider and not tapered anteriorly; entoplastron gracile; skull wide, with broadly triangular face and blunt snout in dorsal view; face deep in lateral view; anterior edge of prefrontals shallowly emarginated laterally;....angle between anterior face of dentary symphysis and dorsal edge of labial ridge 30-40 degrees; dentary pockets broad and deep. Further differs from $A$. [Aspideretoides] allani in retaining sculpted plastral callosities and unfused hyoplastron and hypoplastron." Unlike Campanian specimens described by Gard- 
ner et al. (1995), Maastrichtian specimens of Axestemys splendida may have a smooth, unsculpted skull roof.

\section{Description of New Material}

Cranium. Figure 7. The right half of the skull is crushed, and the secondary palate is broken, but the fossil is otherwise complete. From the premaxilla to the end of the supraoccipital, the skull is 20.5 $\mathrm{cm}$ long. The roof of the skull is smooth, unlike that of the Campanian specimens of this species (Gardner et al., 1995).

Premaxilla. The premaxillae are fused into a single element. They make up part of the anterior margin of the skull and are otherwise surrounded by the maxillae. They do not enter the apertura narium externa.

Maxilla. The maxillae are deep and short. They make up part of the margin of the orbit and the apertura narium externa. They contact the prefrontals anterior to the orbit and along the anteriomedial margin of the orbit. They contact the jugal ventral to the orbit. The maxillae do not contact the frontals or quadratojugals. Ventrally, the maxillae form a wide, pitted primary palate that contacts the premaxilla. The vomer is visible, but the surface of the secondary palate is broken. The extent to which the vomer contacted the maxillae is unknown. Matrix obscures the foramen intermaxillaris.

Prefrontal. The prefrontal makes up part of the margin of the orbit and the apertura narium externa. The dorsal edge of the apertura narium externa is weakly emarginated laterally, but not at all emarginated medially. The prefrontal does not contact the palatine. In dorsal view, the prefrontals contact the maxillae laterally, the frontals posteriorly, and, within the orbit, the vomer.

Frontal. The frontals are roughly trapezoidal. They make up the posteromedial margin of the orbit. On the skull surface they contact the prefrontals anteriorly and the parietals posteriorly. They have a short lateral contact with the postorbitals near the orbital margin. Within the orbit, the frontals remain unfused and contact the prefrontals in a suture that is relatively straight dorsoventrally, unlike specimens of Gilmoremys lancensis. The sulcus olfactorius is present as a long ventral depression where the two frontals contact each other.

Parietal. On the skull roof, the parietals contact the frontals anteriorly and the postorbitals anterolaterally. Unlike plastomenids, at no point do they participate in the orbital margin, either on the surface or within the skull. Within the fossa temporalis superior, they contact the postorbital and prootic laterally and taper into the supraoccipital. The processus trochlearis oticum is composed of the quadrate, prootic, and parietal. The latter contributes to about $25 \%$ of the process. The parietal forms the anterior part of the margin of the foramen nervi trigemini, but its contacts with other elements in that region are fragmented and unclear.

Postorbital. The postorbitals are large and extend from the margin of the orbit to the upper temporal emargination. They are bounded by the parietals and the frontals medially and the jugals laterally. The contact between the jugal and the postorbital is obscured by cracks, but it is still clear that the postorbitals form the entirety of the surface of the postorbital bar, which is approximately half the diameter of the orbit.

Jugal. The jugal forms part of the lateral margin of the orbit, where it contacts the maxilla anteriorly and the postorbital posteriorly. The postorbital prevents any contact between the jugal and parietal, including below the surface of the skull. The jugal contacts the quadratojugal along the temporal arch, but doest not contact the squamosal. The anterior limit of cheek emargination is formed by the jugal.

Quadratojugal. The quadratojugal forms part of the temporal arch. Laterally, it comprises the posterior third of the arch, contacting the jugal anteriorly and the quadrate and squamosal posteriorly. Medially, the quadratojugal forms about half of the inner surface of the temporal arch.

Squamosal. The squamosal forms the lateral boundary of the fossa temporalis superior. In lateral view, it contacts the quadratojugal anteriorly and the quadrate ventrally, roofs the cavum tympanum, and forms most of the antrum postoticum.

In dorsal view, the squamosal forms a small, accessory ridge along the top of the otic capsule, and contacts the quadrate and opisthotic medially along the length of the otic capsule. The squamosal probably contacted the paroccipital process of the opisthotic, but that region is broken. Posterior to the otic capsule, the squamosal forms a long, thin process.

Vomer. The edges of the vomer are broken both within the orbit and in palatal view. The anterior contacts with the maxillae are either broken or obscured by matrix. In palatal view, the remains of the vomer extend between the choanae and partially separate the palatines. They do not contact the pterygoids. 
Palatine. In palatal view, the palatines contact the vomer anteriorly and form the posterior margin of the choanae anterolaterally. A single, large foramen palatinum posterius forms on either side of the palate at the contact between the maxillae and palatines. Posterolaterally, the palatines contact the pterygoids, and between the pterygoids the palatines have a short contact with the basisphenoid.

Laterally, the palatine contacts the jugal and maxilla anteriorly, both within the fossa temporalis inferior and within the orbit. Posterior to the orbit, the medial margin of the palatine contacts the vomer ventrally, forms part of the wall of the braincase, and contacts the parietal dorsally. The posterior part of the braincase wall and the floor of the fossa temporalis inferior are fragmented. Although the palatine appears to be present there, its contacts with other bones in that region are unclear.

Pterygoid. The pterygoid forms part of the floor of the fossa temporalis inferior, but the extent of that contribution and any possible contribution to the foramen nervi trigemini is unclear owing to the highly fragmented bone in the region. In palatal view, the pterygoids have a long, crescent-shaped contact with the maxillae anteriorly, and a medial contact with the palatines, the basisphenoid, and the basioccipital. Posterolaterally, they contact the quadrates. The foramen posterius canalis carotici interni is surrounded by the pterygoid and positioned posteriorly in palatal view, below the basioccipital tubercle.

In posterior view, the pterygoid contacts the quadrate laterally, the opisthotic dorsally, and the exoccipital medially. The fenestra postotica is crushed, but there is no apparent process that would exclude the foramen jugulare posterius from the fenestra postotica, either from the pterygoid or the opisthotic.

Basisphenoid. The basisphenoid is triangular, without any sort of constriction along the bone. It contacts the palatines anteriorly, the pterygoids laterally, and the basioccipital posteriorly.

Prootic. In dorsal view, the prootic forms the majority of the processus trochlearis oticum. It contacts the parietal medially and the supraoccipital posteromedially along a short suture. Dorsally, it contacts the opisthotic, and laterally it contacts the quadrate. It forms almost the entirety of the foramen stapedio-temporale. Within the fossa temporalis inferior, the prootic forms the dorsal margin of the foramen nervi trigemini and contacts the parietal anteriorly. Posterior contacts are obscured.
Epipterygoid. The region anterior to the foramen nervi trigemini is fragmented, and the location of the epipterygoid, if it is present, is unclear.

Opisthotic. In dorsal view, the opisthotic forms the posterior margin of the skull between the squamosal and the supraoccipital. Anteriorly it contacts the prootic and medially it contacts the supraoccipital. Laterally it contacts the quadrate. Broken edges of the skull indicate that the opisthotic had a paraoccipital process that contacted the squamosal.

In posterior view, the opisthotic contacts the exoccipital medially and the pterygoid ventrally. The opisthotic does not participate in any subdivision of the fenestra postotica (see above).

Quadrate. The quadrate makes up most of the cavum tympani and encloses the incisura columnella auris. In lateral view, the quadrate contacts the quadratojugal anteriorly, the squamosal anteriorly and posteriorly along the roof of the cavum tympani, and makes up the ventral margin of the cavum tympani. In dorsal view, the quadrate contacts the squamosal laterally and the prootic and opisthotic medially. It contributes to part of the lateral wall of the foramen stapedio-temporale. In ventral view, the quadrate contacts the quadratojugal anteriorly, the prootic anteromedially, the pterygoid posteromedially and the squamosal posteriorly.

Basioccipital. The basioccipital makes up the ventral third of the occipital condyle. The bones of forming the occipital condyle are not fused. In ventral view, it contacts the basisphenoid anteriorly and the pterygoids laterally. The basioccipital contacts the exoccipitals along the dorsal surface of the basioccipital tubercles. The exoccipitals prevent the basioccipital from participating in the foramen magnum.

Exoccipital. The exoccipitals form the dorsal twothirds of the occipital condyle. In posterior view, they form much of the lateral margin of the foramen magnum. The exoccipital contacts the opisthotic laterally, the pterygoid ventrolaterally for a short distance, and the basioccipital along the lateral edge of the dorsal surface of the basioccipital tubercules. The exoccipitals exclude the basioccipital from the foramen magnum.

Supraoccipital. The high crista supraoccipitalis is composed of both the parietal anteriorly and the supraoccipital posteriorly. The supraoccipital is a long, T-shaped bone. In dorsal view, it contacts the parietal anteriorly and the prootic and opisthotic laterally. In posterior view, the supraoccipital forms 
the dorsal margin of the foramen magnum. It contacts the opisthotics laterally and the exoccipitals ventrolaterally.

Mandible. Figure 8. The larger mandible (MRF 666, Figure 8.1-8.6) is complete except for a break between the two lateral halves of the jaw. The smaller mandible (MRF 849, Figure 8.7-8.10) preserves only the complete anterior portion of the dentary.

The mandible has a broad, rugose triturating surface, particularly toward the posterior end of the dentary where the lingual ridge is enlarged into a broad dentary pocket. In lateral view, the triturating surface extends beyond the anterior margin of the rest of the dentary, forming a lip on the dorsal part of the mandible. The coronoid process is relatively high, but much less so than that of Gilmoremys lancensis (Joyce and Lyson, 2011).

Dentary. The dentary forms the anterior half of the jaw, including the triturating surface. In dorsal view the anterior margin of the dentary is bluntly rounded, without the elongation seen in Gilmoremys lancensis. It lacks a symphyseal ridge, but has a pronounced lingual and labial ridge. It contacts the coronoid posteriorly. In lateral view, the posterior end of the dentary contacts the coronoid anterodorsally and the surangular posterodorsally. In medial view, most of the contacts between the dentary and other bones are obscured by a broken region posterior to the coronoid process. The dentary contacts the coronoid anterior to and ventral to the coronoid process, and the angular dorsally.

Angular. Little of the angular is visible. It contacts the dentary ventrally and the prearticular dorsally.

Surangular. In lateral view, the surangular contacts the dentary anteroventrally. It probably contacted the coronoid, but the region where the contact would be expected between the two bones is missing. Two openings for the foramen nervi auriculotemporalis-one large, and one smaller one inside the larger opening - are anteroventral to the area articularis mandibularis. In dorsal view, the surangular contacts the articular medially, makes up just over half of the area articularis mandibularis, and forms the lateral margin of the fossa Meckelii.

Coronoid. The coronoid contacts the dentary anteriorly. In dorsal view it most likely contacted the surangular laterally and the prearticular medially, but the posterior region of the coronoid is broken.

Articular. The articular is poorly preserved. In dorsal view, it forms just under half of the area articu- laris mandibularis and contacts the surangular laterally.

Prearticular. A large part of the prearticular is present, but contacts between the prearticular and other bones are poorly preserved. It contacts the angular ventrally.

Carapace. Figures 9, 10. The larger carapace (MRF 835, Figure 9) is $70 \mathrm{~cm}$ long along the midline. The medial region of the larger carapace, including the neurals, weathered away before the specimen was discovered and collected, leaving only the nuchal and the lateral parts of the costals. Preparation exposed the ventral side of the carapace, but the dorsal side remains unprepared. The posterior half of the smaller carapace was found articulated, including left third and fourth costals, and both fifth through eighth costals. The preneural, right first, second, and fourth costals, were all found in the same quarry. A reconstruction of the complete carapace is approximately $55 \mathrm{~cm}$ long (MRF 849, Figure 10). The larger carapace is circular in outline, while the smaller carapace probably had a subrectangular outline when complete. Neither has any kind of waist or significant emargination, unlike Hutchemys arctochelys (Joyce et al., 2009). The lateral margins of the larger carapace are straight, while the posterior margin is incompletely preserved. The lateral margins and posterior border of the smaller carapace are straight.

Sculpturing on the smaller carapace is similar to that on the type specimen of Axestemys splendida. It consists of thin ridges in either a net-like pattern or in wavy lines with wide furrows in between. Near the sutures with other bones, the pattern becomes more regular, with straight lines of subrectangular pits surrounded by the same, thin ridges. Sculpturing covers all but a narrow, approximately $1 \mathrm{~cm}$ margin of the external surface of the carapace. Unlike Hutchemys arctochelys (Joyce et al., 2009), the visceral portion of the carapace lacks a callosity and is completely smooth.

Nuchal. The nuchal is approximately five times wider than long. Unlike cyclanorbines, MRF 835 lacks a posterior costiform processes, and there is no evidence of a prenuchal. The anteromedial margin of the nuchal is slightly emarginated, but not to the extreme degree seen in the "Trionyx" kansaiensis or Hutchemys rememdium (Joyce et al., 2009; Vitek and Danilov, 2010). The first thoracic vertebra is situated in the middle of the nuchal. The partially preserved nuchal of the larger carapace as well as the first costal (MRF 631) and 

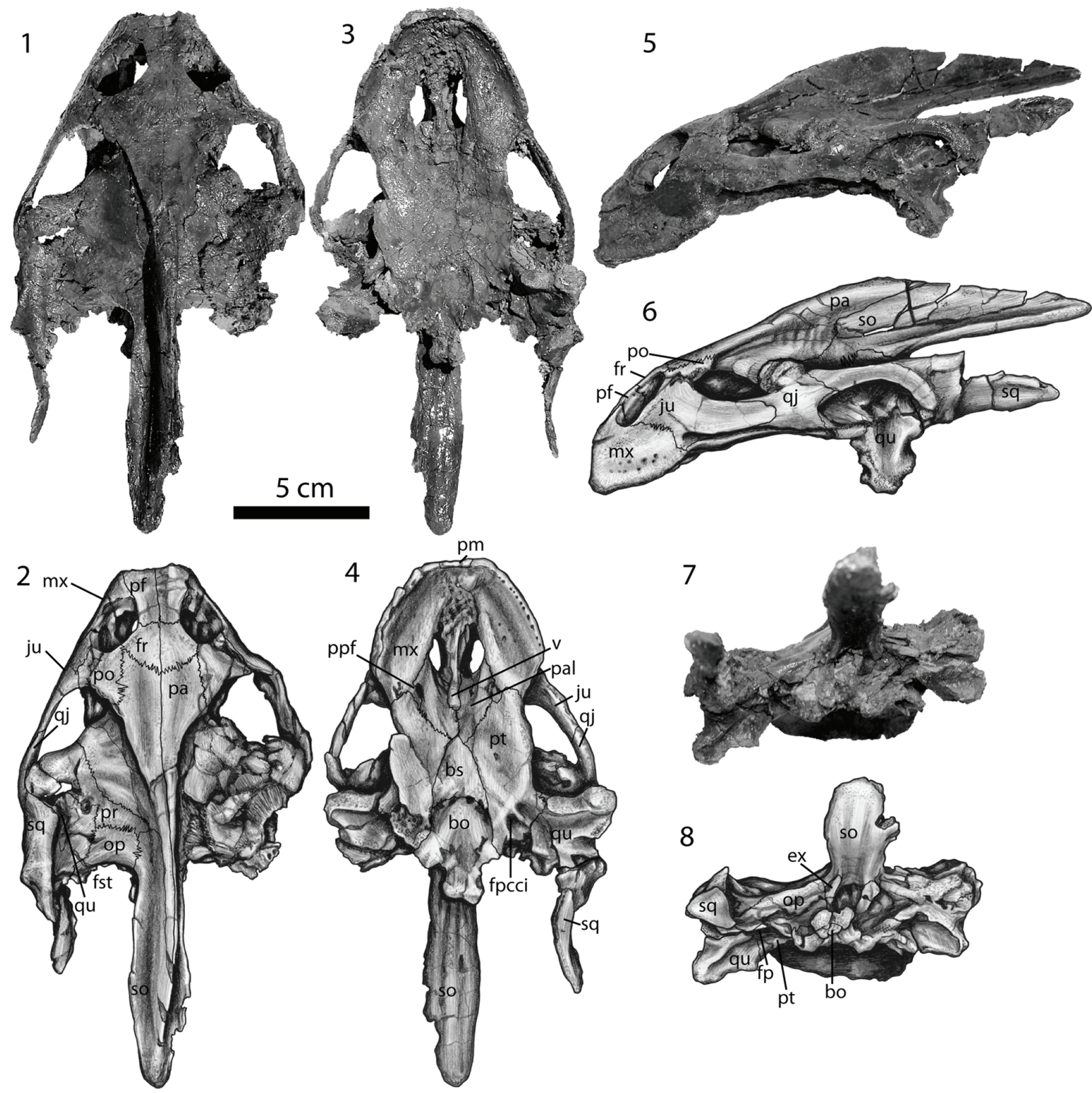

FIGURE 8. MRF 266, skull of Axestemys splendida from the Cretaceous Hell Creek Formation of North Dakota. 1, photograph and 2, illustration of dorsal view. 3, photograph and 4, illustration of ventral view. 5, photograph and 6, illustration of lateral view. 7 , photograph and 8, illustration of posterior view. Abbreviations: bo $=$ basioccipital, bs $=$

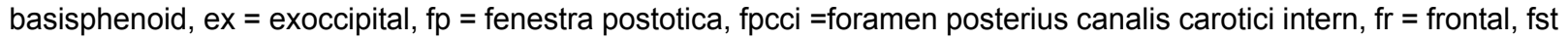
= foramen stapedio-temporale, $\mathrm{ju}=$ jugal, $\mathrm{mx}=$ maxilla, op = opisthotic, $\mathrm{pa}=$ parietal, pal $=$ palatine, pf $=$ prefrontal, $\mathrm{pm}=$ premaxilla, $\mathrm{po}=$ postorbital, $\mathrm{ppf}=$ foramen palatine posterius, $\mathrm{pr}=$ prootic, $\mathrm{pt}=$ pterygoid, $\mathrm{qj}=$ quadratojugal, $\mathrm{qu}$ $=$ quadrate, $\mathrm{so}=$ supraoccipital, $\mathrm{sq}=$ squamosal, $\mathrm{v}=$ vomer .

preneural (MRF 700) of the smaller carapace indicate that the nuchal was completely sutured to the first costals and preneural without any suprascapular fontanelles. The first costal ribs overlap part the visceral surface of the nuchal.

Neurals. Although not all of the neurals in either carapace are preserved, the posterior portion of the smaller carapace indicates that seven neurals were present in addition to a preneural (eight neurals with neurals 1 and 2 unfused in Meylan's terminology). The preneural is large and roughly trapezoidal. Neurals 3-6 are hexagonal with short posterolateral sides, and neurals 1 and 2 were probably similarly shaped. The posterior edge of 

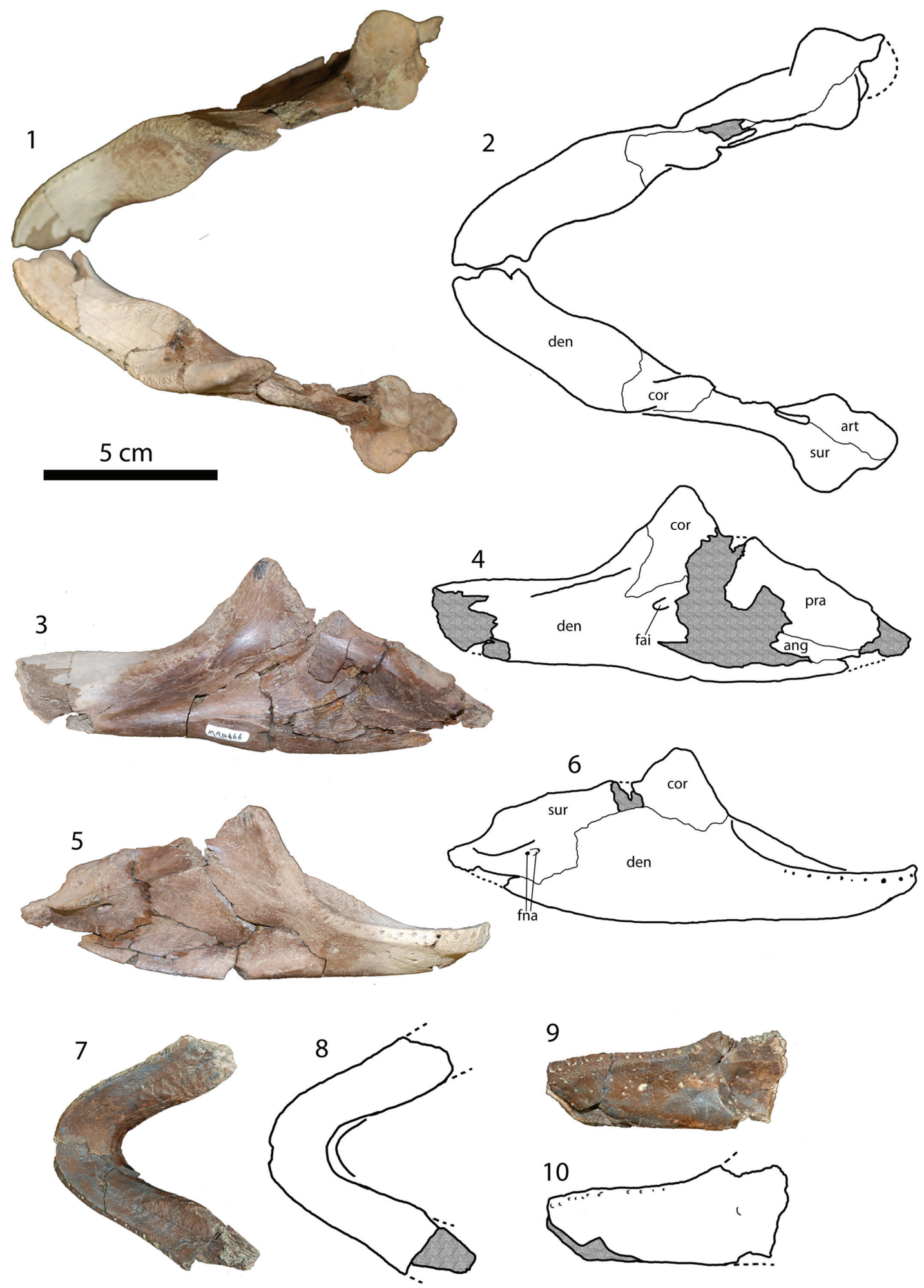

FIGURE 9. Mandibles of Axestemys splendida from Cretaceous Hell Creek Formation of North Dakota. MRF 666, 1, photograph and 2, illustration of dorsal view. 3, photograph and 4, illustration of medial view. 5, photograph and 6, illustration of lateral view. MRF 849, 7. photograph and 8, illustration of dorsal view. 9, photograph and 10, illustration of lateral view. Abbreviations: ang = angular, art = articular, cor = coronoid, den = dentary, fai $=$ foramen alveolare inferius, fna $=$ foramen nervi auriculotemporalis, pra $=$ prearticular, sur $=$ surangular. 

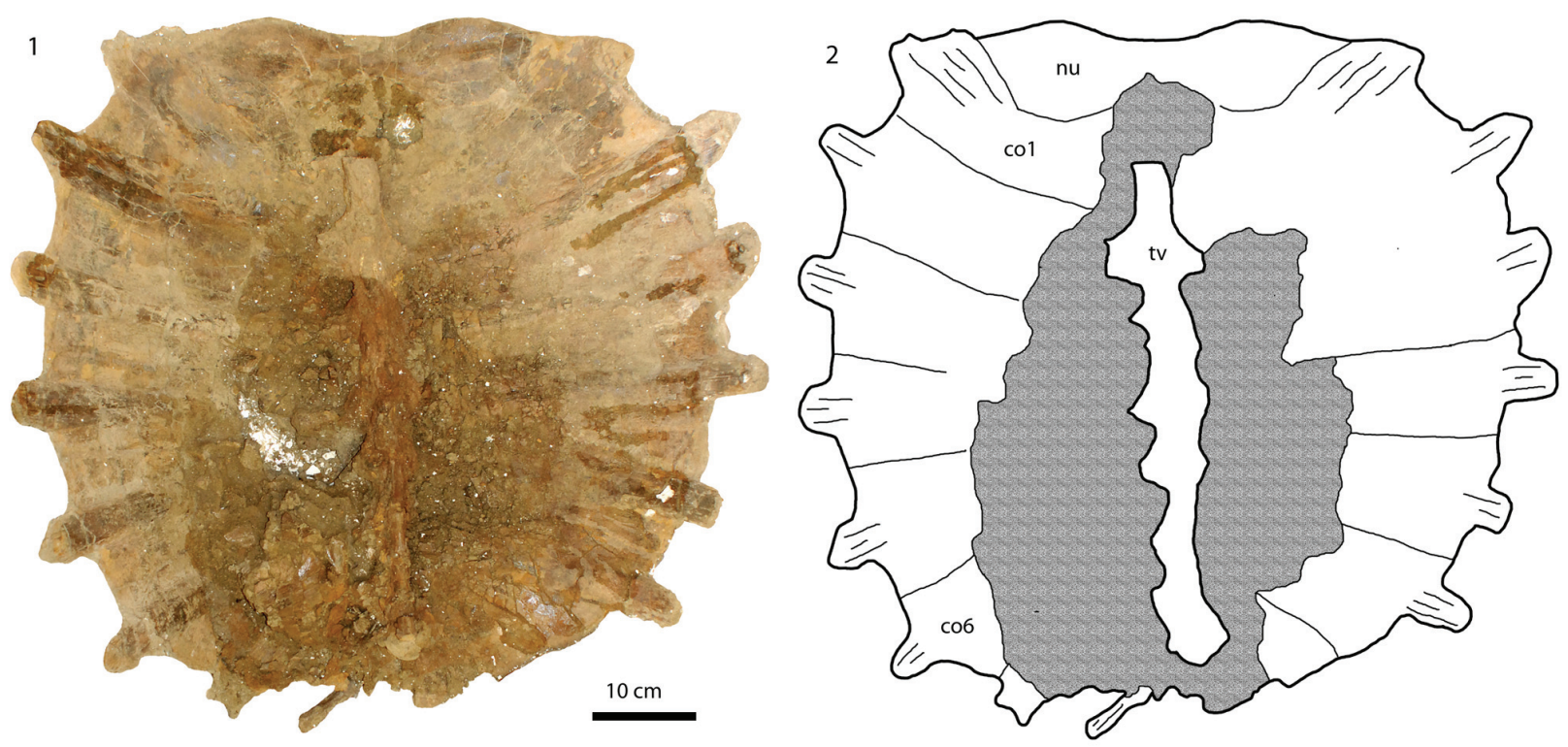

FIGURE 10. MRF 835 carapace of Axestemys splendida from the Cretaceous Hell Creek Formation of North Dakota. 1, photograph and 2, illustration of visceral view. Shaded areas indicate fragmented regions. Abbreviations: $\mathrm{co}=$ costal, $\mathrm{nu}=$ nuchal, $\mathrm{tv}=$ thoracic vertebrae.

neurals 5 and 6 are posterior to the posterior edge of the fifth and sixth costals, respectively. Throughout the neural column, there is no neural reversal. The seventh neural is reduced and oval-shaped.

Costals. Eight pairs of costals are present. The distal margins of the costals are rounded. Rib ends extend as much as $10 \mathrm{~cm}$ from the margin of the smaller carapace and $6 \mathrm{~cm}$ from the margin of the larger carapace. The first pairs of costals have lateral margins neither reduced nor expanded, unlike extinct trionychid species such as Gilmoremys lancensis. The eighth pair is reduced and wider than it is long. The seventh costals meet partially at the midline, the eighth costals meet entirely at the midline, and both seventh and eighth costals make up the posterior border of the carapace. The visceral surfaces of the eighth costals are smooth, without a depression for the ilia.

Plastron. Figure 11. A left hyoplastron and hypoplastron, MRF 834, were found sutured together underneath the larger shell (MRF 835, described above). Three additional hyoplastra were found in the same quarry. No epiplastra, entoplastra, or xiphiplastra attributable to this species were recovered.

Both the hyoplastra and hypoplastra are covered in a sculptured callosity. The callosity does not cover the lateral and medial processes, nor does it form an anterior plastomenid-type "shoulder" or extend beyond the lateral processes. The sculpture pattern is a series of fine ridges that cross each other to form a net-like pattern, identical to the pattern on the carapace. The hyoplastron and hypoplastron are connected by a suture, but unlike Apalone ferox the two bones do not fuse together. The hyoplastral-hypoplastral bridge is short, about one-quarter the maximum width of the hypoplastron. The hyoplastron and hypoplastra do not appear to have met at the midline.

The hyoplastra have a single lateral process and 3-4 medial processes. The single preserved hypoplastron has two lateral processes. The medial processes are divided up into a pair of anteromedial processes then a gap followed by two posteromedial processes that contact the xiphiplastra. Given the arrangement of posteromedial hypoplastral processes, the xiphiplastra can be inferred to have been lateral-most in the hypoxiphiplastral contact.

\section{Remarks}

All of the bones from the Big Turtle Cove locality come from a single, small quarry. All of the trionychid material from the quarry comes in one of two sizes, each corresponding to the larger and smaller carapace described above. There are no extraneous trionychid bones from the quarry that do not correspond to these two individuals, either in terms of characters or in terms of "extra" bones such as two large right hyoplastra that would require two large individuals. In addition, the 

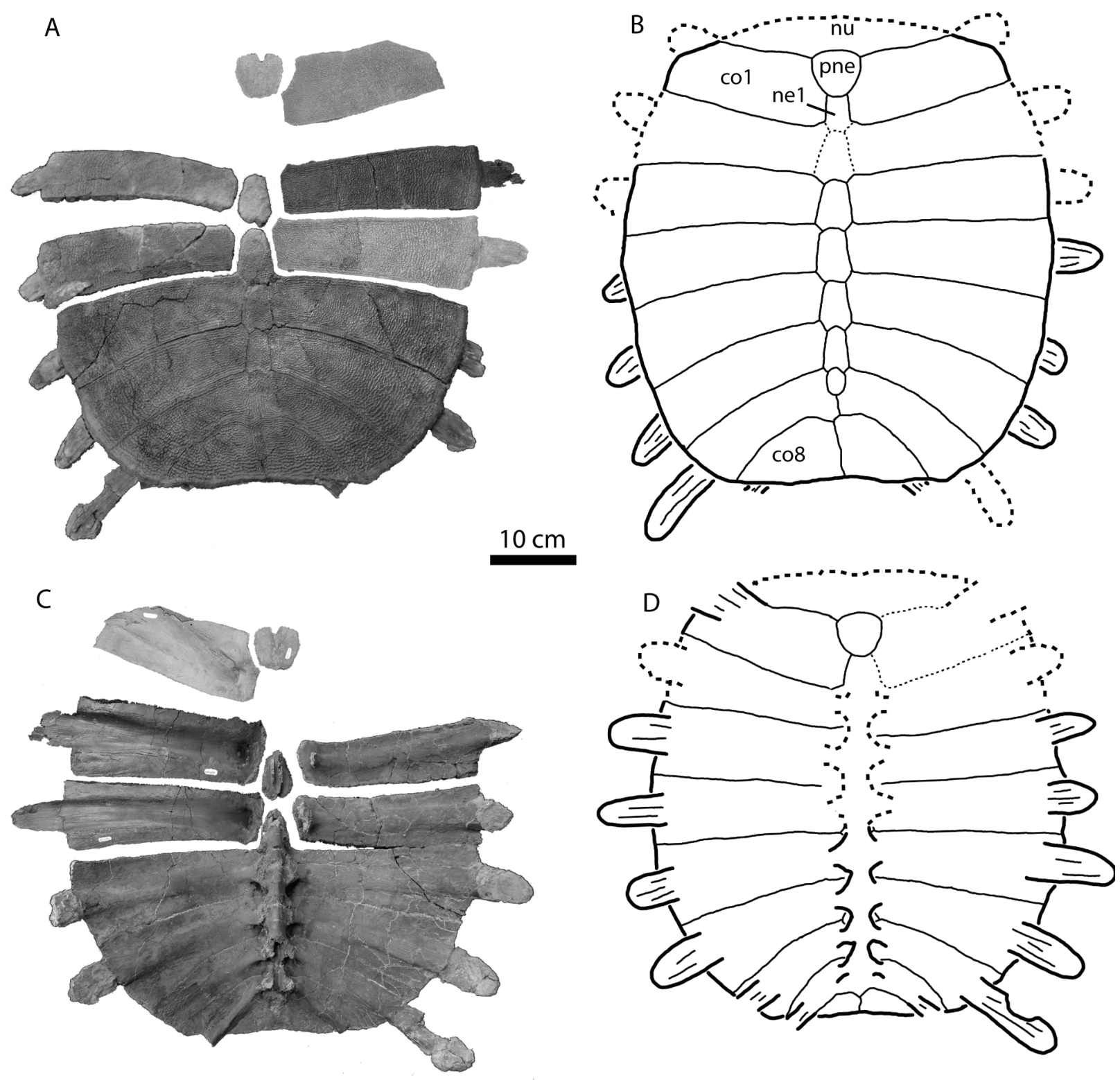

FIGURE 11. MRF 849, MRF 631, MRF 654, MRF 676, MRF 700, carapace of Axestemys splendida from the Cretaceous Hell Creek Formation of North Dakota. 1, photograph and 2, illustration of external view. 3, photograph and 4, illustration of visceral view. Abbreviations: $c o=$ costal, ne = neural, nu = nuchal, pne = preneural.

smaller isolated carapace bones (MRF 631, MRF 654, MRF 676, MRF 700) are identical to the smaller posterior carapace (MRF 849) in terms of size, sculpture pattern, and bone thickness. For these reasons, the smaller carapace bones are inferred as belonging to a single individual in Figure 6 despite not being found in articulation.

The described material is identical to Aspideretoides splendidus as described and diagnosed by Gardner et al. (1995), including characters that were not mentioned in the original diagnosis, such as a single lateral hyoplastral process (variably present in Campanian specimens such as TMP 2001.12.27) and relatively long rib extensions. The exception is the absence of sculpturing on the skull roof in the newly described material (MRF 266). Although sculpturing on the skull roof was considered diagnostic for this species and is absent in MRF 266, the MRF specimen is identical in all other ways to other skulls of Axestemys. splendida.

Axestemys cerevisia sp. nov.

1979 Trionychidae gen. indet. Gaffney p.53, figs. $1-3$. 

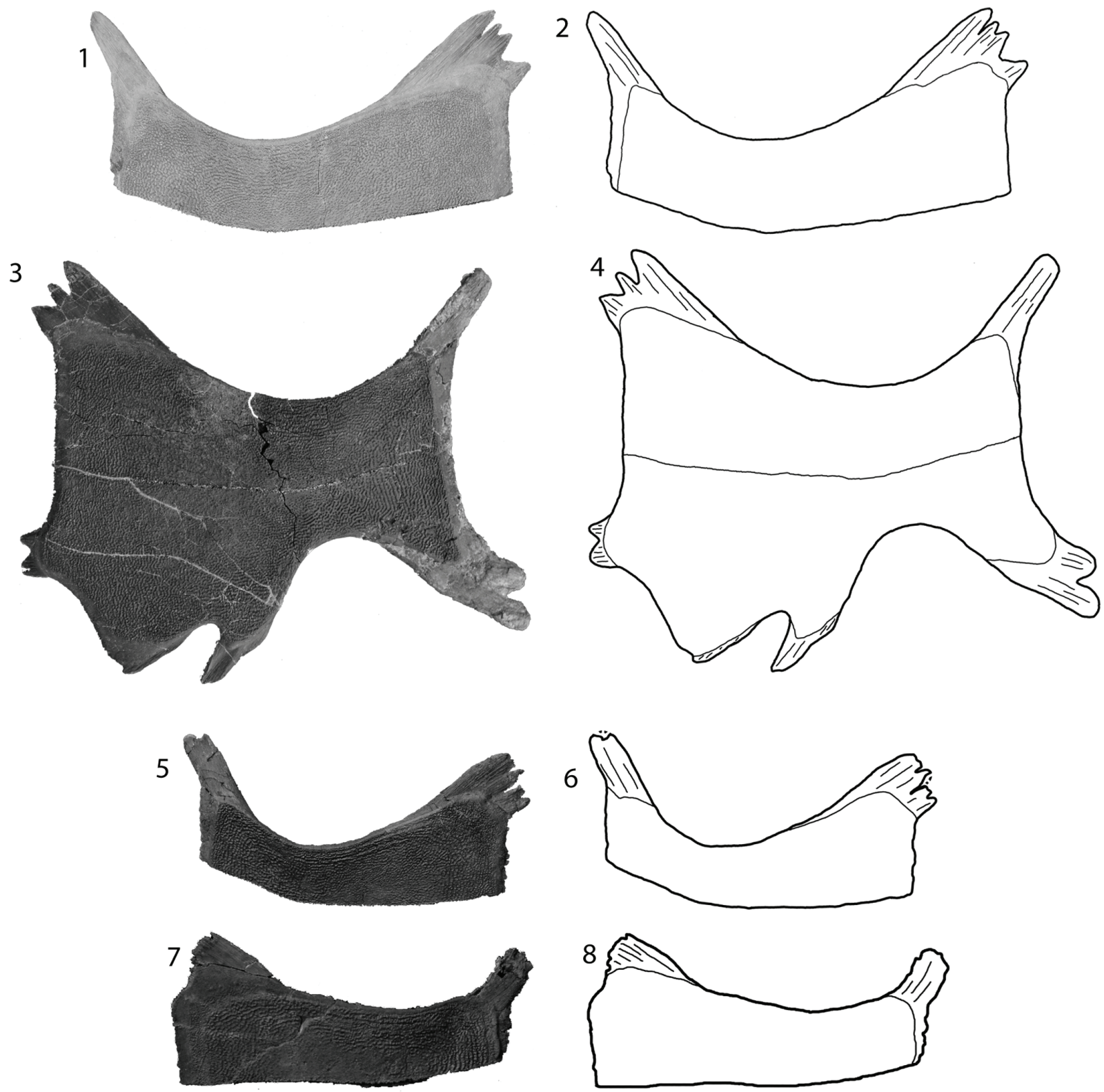

FIGURE 12. Hyoplastra and hypoplastra of Axestemys splendida from the Cretaceous Hell Creek Formation of North Dakota. MRF 678, right hyoplastron, 1, photograph and 2, illustration. MRF 834, left hyoplastron and hypoplastron, 3, photograph and 4, illustration. MRF 675, right hyoplastron, 5, photograph and 6, illustration. MRF 567, left hyoplastron, 7 , photograph and 8 , illustration.

2003 Axestemys sp. indet. Hutchison and Holroyd p. 134.

Figure $7.11,12,13$

\section{Etymology}

From cerevisia, Latin for beer, in reference to the unusual method of data collection for the holotype specimen as reported by E.S. Gaffney: "The only information about the in situ position of the skeletal elements of this specimen is a field sketch made on a Coors beer six-pack container, another demonstration of the essential nature of this sort of field equipment" (Gaffney, 1979, p. 53). 


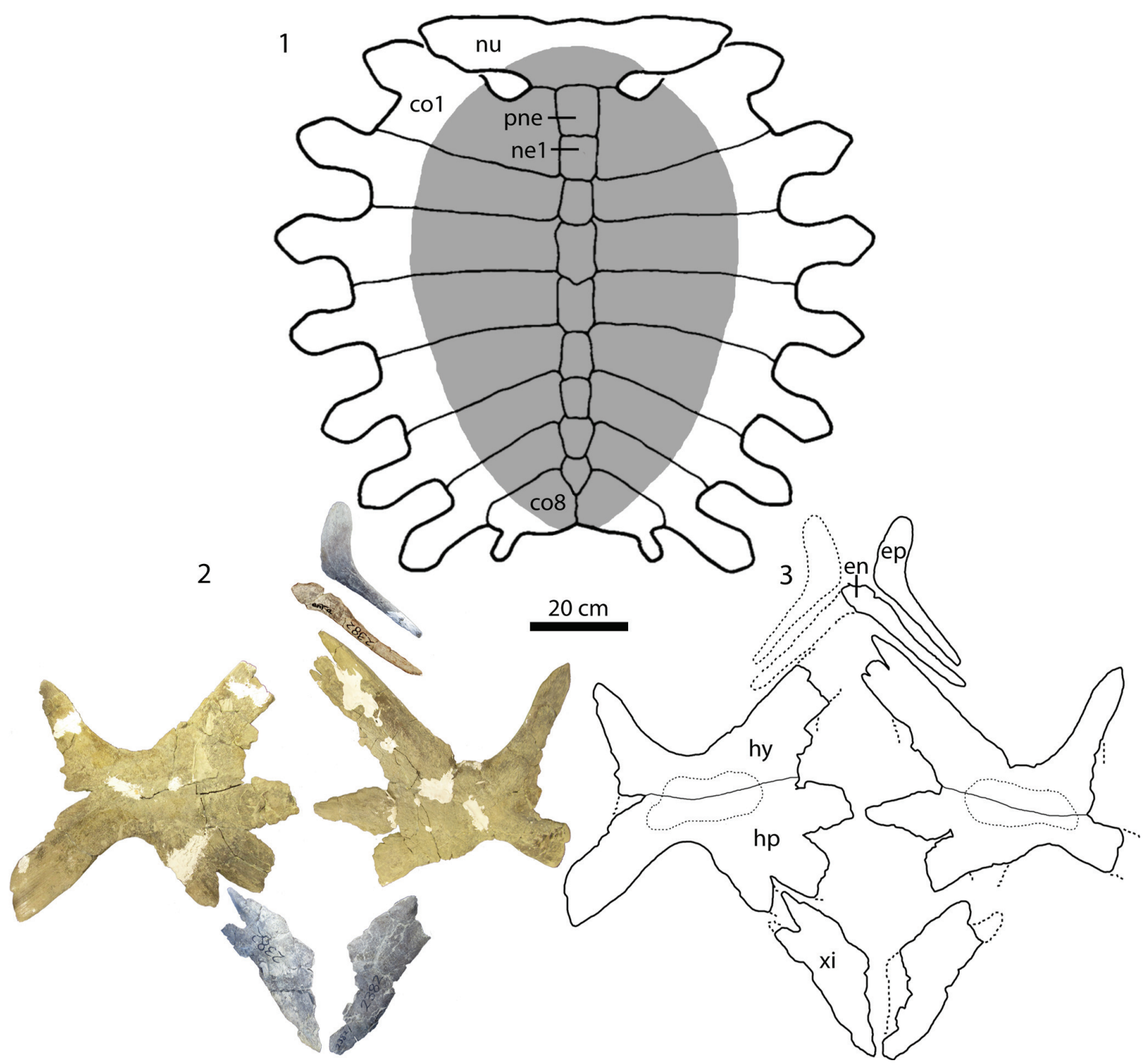

FIGURE 13. UW 2382, holotype of Axestemys cerevisia from the Eocene Bridger Formation of Wyoming. 1, illustration of carapace. Gray area indicates limit of sculpturing. 2, Photograph and 3, illustration of plastron. Dotted line on hyoplastra ad hypoplastra indicates limit of callosity. Abbreviations: en = entoplastron, ep = epiplastron, hp = hypoplastron, hy = hyoplastron. Carapace illustration modified from Gaffney, 1979.

\section{Type Specimen}

UW 2382, a carapace, plastron, partial pectoral and pelvic girdles, and one cervical vertebrae.

\section{Horizon and Type Locality}

University of Wyoming Locality Number V-65004, NE 1/4 SE 1/4 Sec. 35, T 22N, R 113W, NE of Opal, Lincoln County, (Bridgerian) Bridger Formation, Bridger A, Wyoming, USA (Gaffney, 1979).

\section{Differential Diagnosis}

Axestemys cerevisia can be diagnosed as a member of Axestemys by a maximum known carapace length of $97 \mathrm{~cm}$, presence of a preneural, and a single lateral hyoplastral process. Axestemys cerevisia can be differentiated from other member of Axestemys by a wide, smooth border of the carapacial callosity, open suprascapular fontanelles with no suture between the posterolateral edge of nuchal and the first costals, smooth and reduced hyoplastral-hypoplastral callosities, and absence of xiphiplastral callosities. 


\section{Description}

A detailed description of the holotype specimen is already published (Gaffney, 1979). Little needs to be changed or added to that description with the exception of the following. Contrary to the previously published description, a small callosity is present on each hyoplastron and hypoplastron. It does not reach any of the margins of the bone or the processes. Its presence is indicated by a raised area in the middle of each element, which, unlike the bare, uncallosified bone, has a smooth surface with occasional cross-hatching, similar to that described in the plastron of Axestemys byssina. In addition, distinct dorsal processes are absent on the single preserved seventh cervical vertebra.

\section{Remarks}

The first published description of this specimen provided locality and stratigraphic information, a description of the specimen, and a comparison with several other fossil and extant trionychids, but the specimen was not named (Gaffney, 1979). Instead, the specimen was referred to the taxon to Trionychidae gen. indet, with a note that the state of trionychid systematics was so disordered at that time that assigning a name to the specimen would be meaningless (Gaffney, 1979).

Since then, revisions and phylogenetic studies of both fossil and recent trionychids (Meylan, 1987; Gardner et al., 1995; Joyce and Lyson, 2011; Joyce et al., 2009; Vitek, 2011) have made inroads into examining phylogenetic relationships and providing a meaningful taxonomy within North American Trionychidae. Although much work remains to be done, the current state of trionychid systematics is at a point where it is now not only apparent that UW 2382 represents a unique species (Gaffney, 1979), but that this taxon is a part of Axestemys. Axestemys cerevisia differs from Axestemys byssina, another Bridgerian species of Axestemys, in having large, open suprascapular fontanelles that prevent a suture between the nuchal and the first costals, less extremely reduced eighth costals, the absence of a callosity on the xiphiplastra, and extensive reduction of the callosity on the hyoplastron and hypoplastron.

\section{Axestemys montinsana sp. nov.}

2003 Axestemys cf. A. puercensis Hutchison and Holroyd p. 133, figs. 7F, H-I, 11A-D.

Figures $7.1-7.9,14,15,16,17,18$

\section{Etymology}

Mont-, Latin for 'mountain,' and insana, Latin for 'crazy,' in reference to the Crazy Mountains Basin in which the type specimen was discovered.

\section{Type Specimen}

UMMP 27029, a skull, partial lower jaw, partial carapace, fragmentary entoplastron, hyoplastron, and hypoplastron, xiphiplastron, five cervical vertebrae, a partial pelvic girdle, two humeri, a femur, and various disarticulated appendicular elements.

\section{Horizon and Type Locality}

Scarritt Quarry, (early Tiffanian, Ti2) Melville Formation, eastern Crazy Mountains Basin, Montana, USA. Discovered by E. Robinson, collected by D.R. Krause 1985 (D.R. Krause, personal commun., 2011; Scott and Krause, 2006).

\section{Referred Material}

PTRM 5350.88, skull fragments; PTRM 5350.23, PTM 5350.24, lower jaw; PTRM 6030.07, PTRM 6030.08, epiplastron; PTRM 6030.01, entoplastron; PTRM 6030.03, hyoplastron; PTRM 6030.04, hypoplastron; PTRM 6030.02, hyoplastron and hypoplastron; PTRM 6030.05, PTRM 6030.06, xiphiplastron; PTRM 5350.21, PTRM 5350.22, PTRM 5350.30, PTRM 5350.108, cervical vertebra; PTRM 5350.91, PTRM 5350.100, pectoral girdle; PTRM 5350.25, humerus; PTRM 5350.21, pelvic girdle, PTRM 5350.77,5350.78, ilium; PTRM 5350.27, ischium, PTRM 5350.75, PTRM 5350.76, pubis; PTRM 5350.28, PTRM 5350.51, PTRM 5350.130, femur; PTRM 5350.122, tibia; PTRM 5350.47, PTRM 5350.110, PTRM 5350.117, 5350.117, PTRM 5350.121, phalanx; PTRM 5350.43, PTRM 5350.105, distal phalanx; all material from PTRM Site V02017, Slope County, North Dakota, USA; Fort Union Formation, early Paleocene (Puercan; Bercovici et al.; 2009).

UCM 49231, skull fragments; UCM 49228, partial dentary; DMNH 44623, costal and plastron fragments; UCM 37755, costal fragments and partial cervical vertebra; DMNH 45130, shell fragments and phalanges; DMNH 44622, plastron fragments and ungual phalanx; DMNH 43187, partial pectoral girdle; UCM 34134, humerus; UCM 34119, phalanx; all material from Colorado, USA; Denver Formation, early Paleocene (Puercan).

\section{Distribution}

Denver Formation (Puercan) of Colorado, Fort Union Formation (Puercan) of North Dakota, and Melville Formation (Tiffanian) of Montana. 

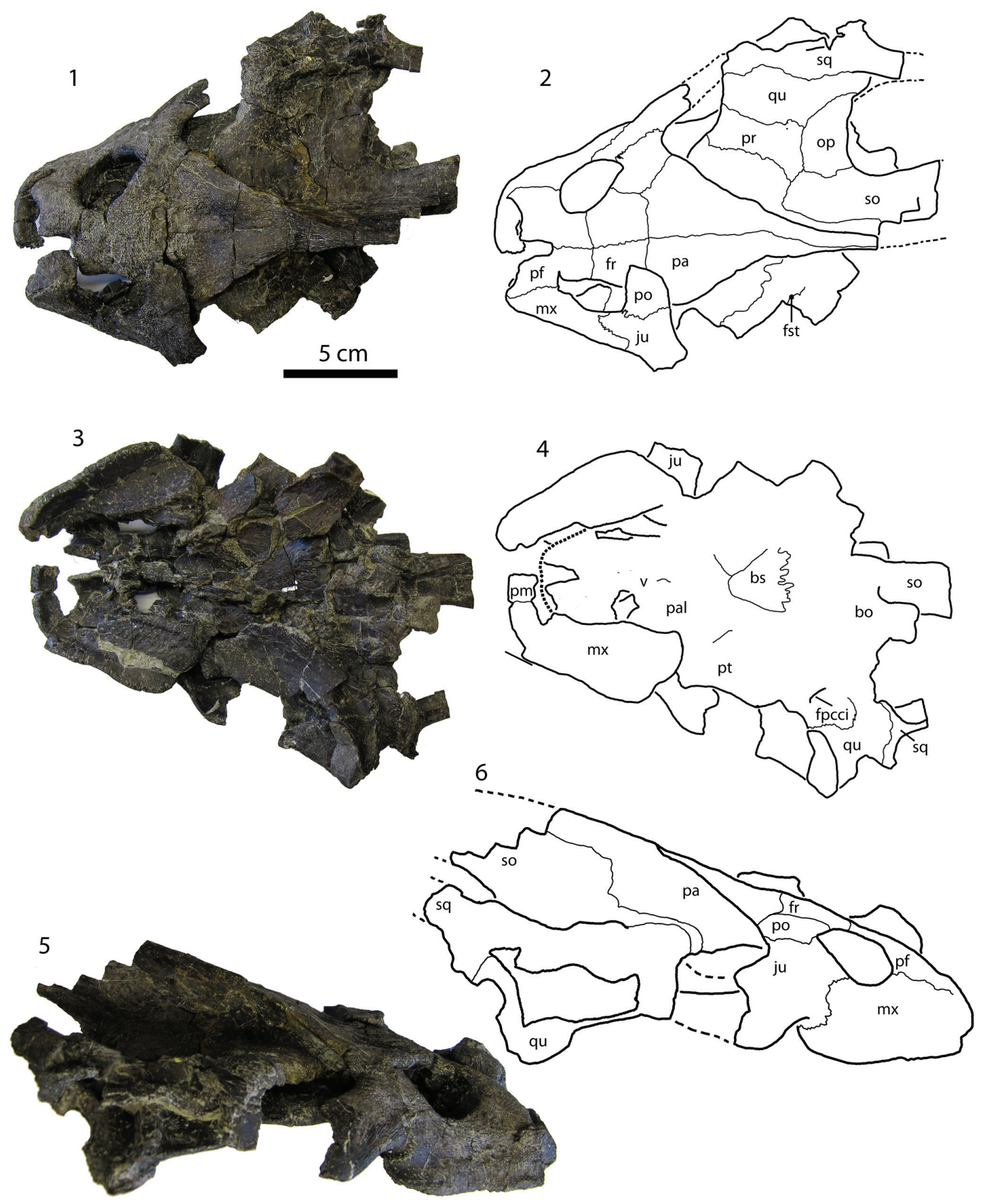

FIGURE 14. UMMP 27029, skull of Axestemys montinsana from the Paleocene Melville Formation of Montana. 1, photograph and 2, illustration of dorsal view. 3, photograph and 4, illustration of ventral view. 5, photograph and 6, illustration of lateral view. Abbreviations: bo = basioccipital, $b s=$ basisphenoid, fpcci =foramen posterius canalis carotici intern, $\mathrm{fr}=$ frontal, $\mathrm{fst}=$ foramen stapedio-temporale, $\mathrm{ju}=$ jugal, $\mathrm{mx}=$ maxilla, op $=$ opisthotic, $\mathrm{pa}=$ parietal, pal $=$ palatine,$p f=$ prefrontal,$p m=$ premaxilla,$p o=$ postorbital, $p r=$ prootic,$p t=$ pterygoid, qu $=$ quadrate, so $=$ supraoccipital, $\mathrm{sq}=$ squamosal, $\mathrm{v}=$ vomer. 

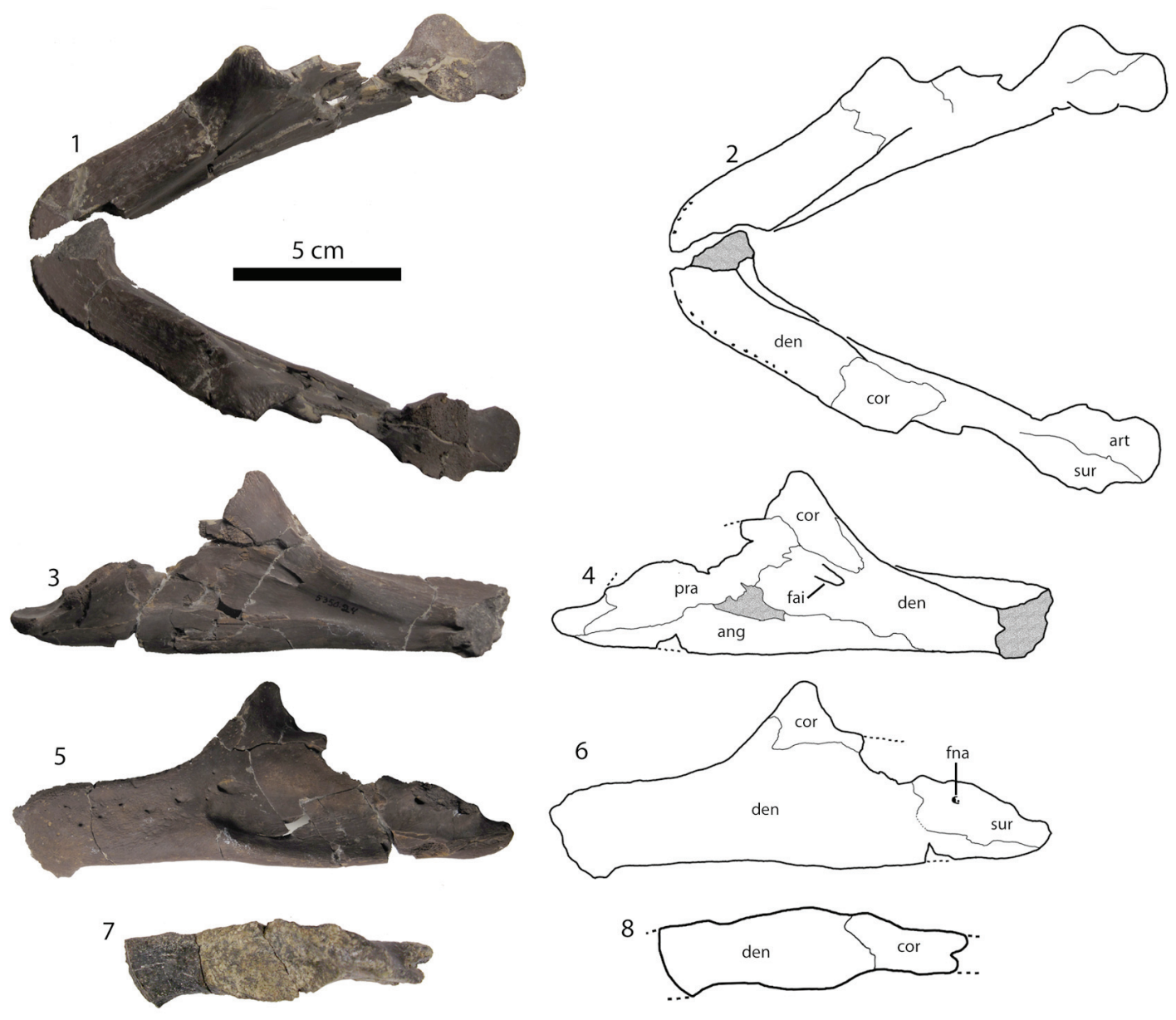

8
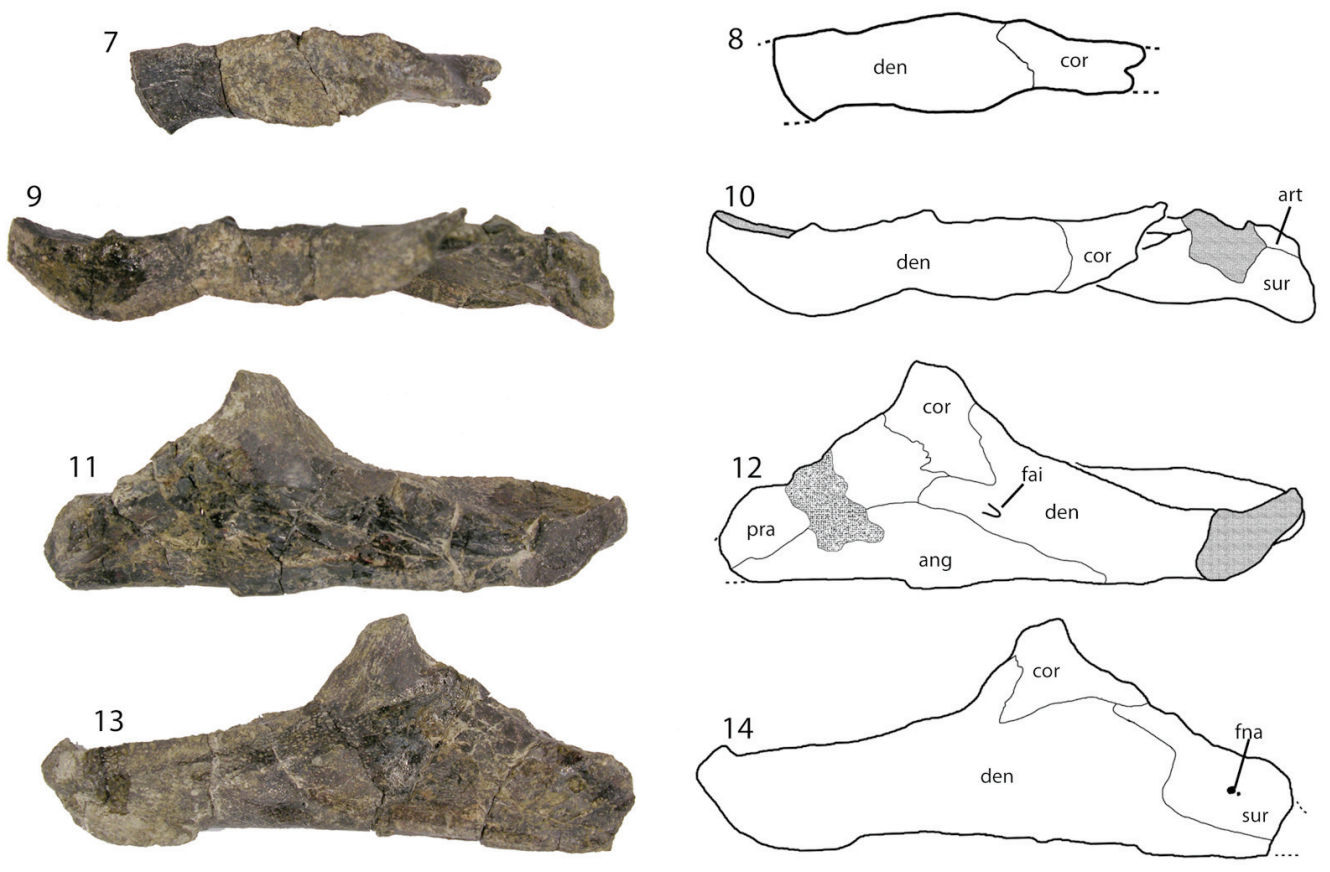

FIGURE 15. Mandibles of Axestemys montinsana. PTRM 5350.23 and PTRM 5350.24, 1, photograph and 2, illustration of dorsal view. PTRM 5350.24, 3, photograph and 4, illustration of medial view. 5, photograph and 6, illustration of lateral view. UMMP 27029, 7, photograph and 8, illustration of right dentary pocket and coronoid in dorsal view. 9 , photograph and 10, illustration of left half of dentary in dorsal view. 11, photograph and 12, illustration of medial view. 13, photograph and 14, illustration of lateral view. Abbreviations: ang = angular, art $=$ articular, cor $=$ coronoid, den $=$ dentary, fai $=$ foramen alveolare inferius, fna $=$ foramen nervi auriculotemporalis, pra = prearticular, sur $=$ surangular. 

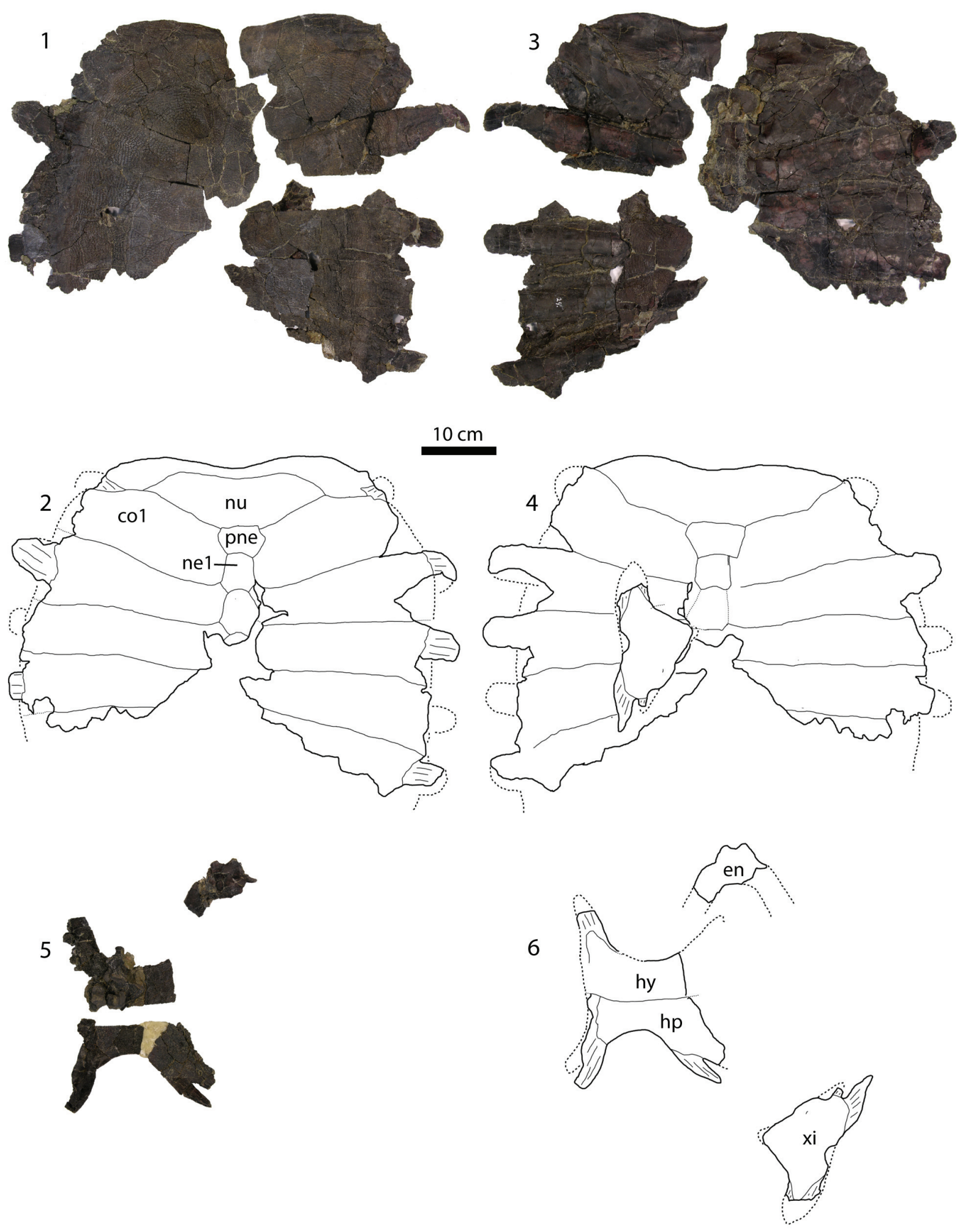

FIGURE 16. UMMP 27029, carapace and plastron of Axestemys montinsana from the Paleocene Melville Formation of Montana. 1, photograph and 2, illustration of carapace external view. 3, photograph and 4, illustration of carapace in visceral view and left xiphiplastron. 5 . photograph and 6. illustration of plastron. Abbreviations: $\operatorname{co}=\operatorname{costal}$, en $=$ entoplastron, $\mathrm{hp}=$ hypoplastron, hy = hyoplastron, $\mathrm{ne}=$ neural, $\mathrm{nu}=$ nuchal, $\mathrm{pne}=$ preneural, $\mathrm{xi}=$ xiphiplastron 

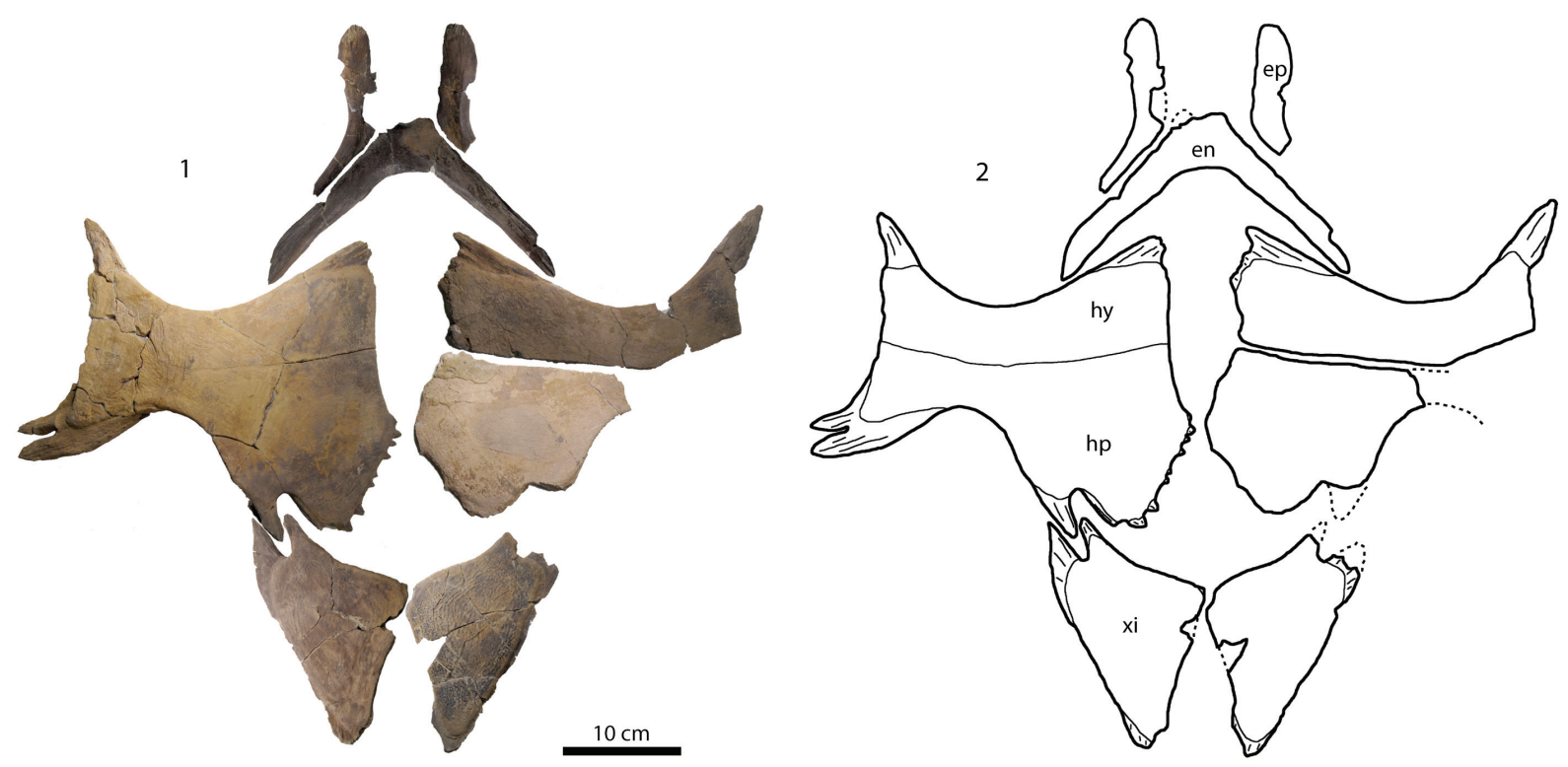

FIGURE 17. PTRM 6030.01-6030.08, plastron of Axestemys montinsana from the Paleocene Fort Union Formation of North Dakota. 1, photograph and 2, illustration. Abbreviations: en = entoplastron, ep = epiplastron, hp = hypoplastron, hy $=$ hyoplastron, $x i=x i p h i p l a s t r o n$.

\section{Differential Diagnosis}

Axestemys montinsana is diagnosed as a member of Axestemys by a maximum carapace length of at least $60 \mathrm{~cm}$, presence of sculpturing on the skull roof, a blunt and triangular skull, a broad and rugose triturating surface, deep maxillae, presence of a preneural, and a single hyoplastral process. Axestemys montinsana can be differentiated from other members of Axestemys by the unique combination of a wide, smooth, unsculptured border around the carapacial callosity, the absence of suprascapular fontanelles, a smooth hyoplastralhypoplastral callosity but sculptured xiphiplastral callosity, and dorsal processes on cervical vertebrae.

\section{Description}

Cranium. Figure 14. The skull is severely crushed and flattened. Both quadratojugals are missing, as well as the left region of the skull posterior to the fossa temporalis superior and much of the supraoccipital. The palate is heavily fragmented. The fossa temporalis inferior is crushed underneath the fossa temporalis superior and bones in that region are not visible. The exterior of the skull has a sculpturing pattern, similar to that found on the skull roof of Campanian specimens of Axestemys splendida (Gardner et al., 1995).
Premaxilla. The premaxillae are fused into a single element, although the bone is broken into two unequal pieces. They form part of the anterior margin of the skull and do not enter the apertura narium externa.

Maxilla. The maxillae form parts of the ventral margins of the orbit and the lateral margin of the apertura narium externa. They contact the prefrontals between the apertura narium externa and the orbit. The maxillae contact the jugals within the ventral wall of the orbits as well as on the external surface of the skull ventral to the orbits. The maxillae do not contact the frontals or quadratojugals.

In ventral view, the maxillae form a deep, pitted primary palate. They contact the premaxillae. The skull is broken along the contact between the maxillae and the pterygoids, although the maxillae appear to contact the pterygoids along a short posterior suture. The surface of the vomer and the anteromedial portions of the maxillae are missing. Contact between these bones, as well as the shape of the foramen intermaxillaris, is unclear.

Prefrontal. The prefrontal forms the dorsal margin of the apertura narium externa and the anterior margin of the orbit. The dorsal edge of the apertura narium externa is weakly emarginated laterally and not at all medially. Within the skull, the prefrontals do not contact the palatines. Potential contact between the prefrontals and vomer is unclear 

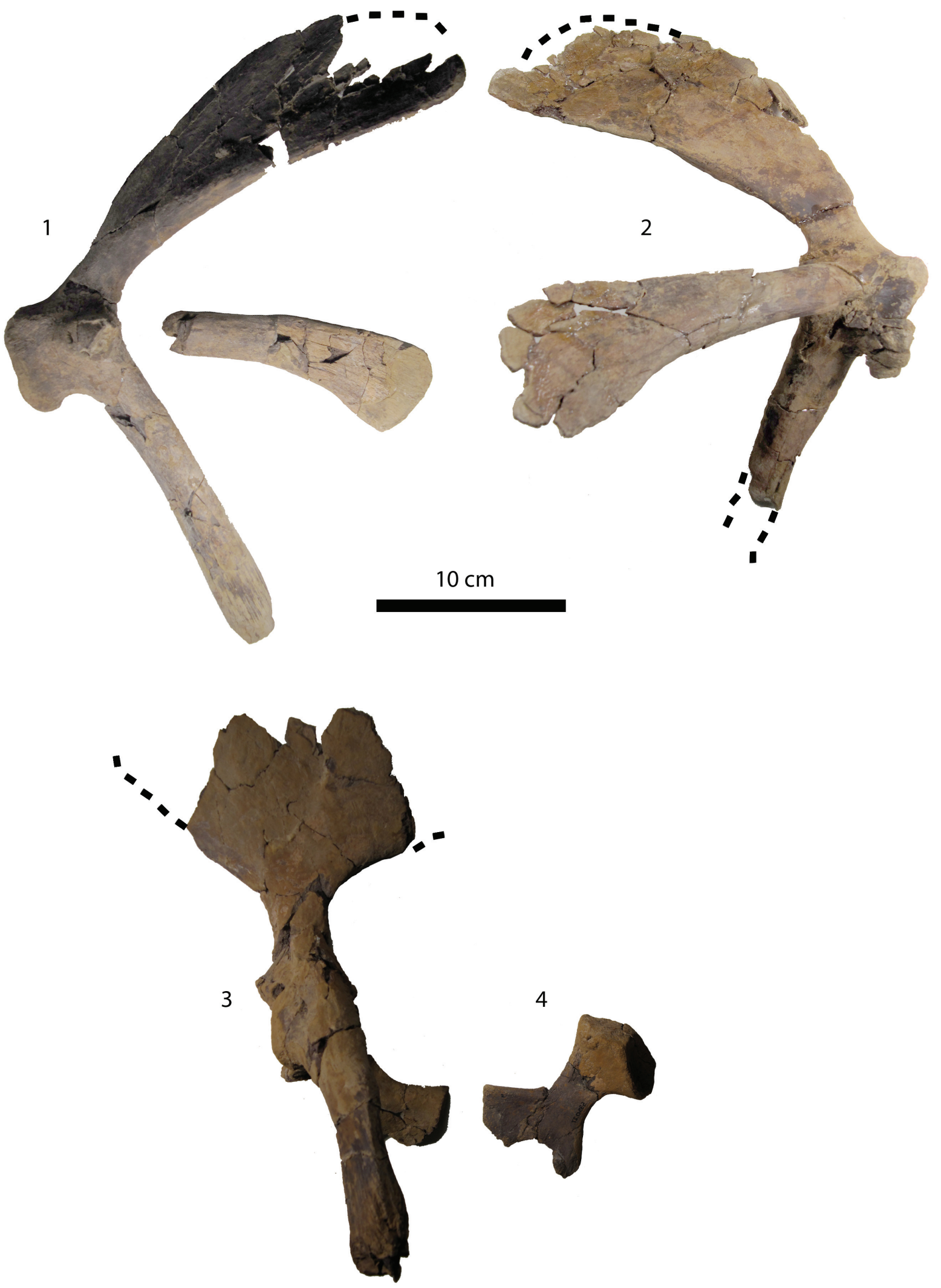

FIGURE 18. Pectoral and pelvic girdle of Axestemys montinsana. Pectoral girdle from the Paleocene Fort Union Formation of North Dakota, 1, PTRM 5350.91, 2, PTRM 5350.100, 3, PTRM 5350.31, pelvic girdle. 4, PTRM 5350.27, ischium. 5, UMMP 27029, pelvic girdle from the Paleocene Melville Formation of Montana. 
because that portion of the skull is sheared in two. In dorsal view, the prefrontals meet along the midline and contact the maxillae laterally and the frontals posteriorly.

Frontal. The frontals are roughly rectangular. On the skull surface, they contact the prefrontals anteriorly, form the posteromedial margin of the orbit, contact the postorbitals posterolaterally along a broad suture, and contact the parietals posteriorly. Within the orbit, the frontals contact each other in a sinuous suture along the midline of the depression of the sulcus olfactorius.

Parietal. In dorsal view, the parietals contact the frontals anteriorly and the postorbitals anterolaterally. Unlike the condition seen in plastomenids, the parietals do not contribute to the margin of the orbit. Within the upper temporal fenestra, the parietals contact the prootic and supraoccipital laterally. The parietal forms about $25 \%$ of the processus trochlearus oticum. The other $75 \%$ is composed of the prootic and quadrate.

Postorbital. The postorbitals are large and form part of both the posterior margin of the orbit, the anterior limit of upper temporal emargination, and therefore the entire postorbital bar. The length of the bar is approximately half the width of the diameter of the orbit. The postorbitals contact the frontals anteromedially, the parietals posteromedially, and the jugals laterally.

Jugal. The jugals form the lateral margin of the orbits and the anterior limit of cheek emargination. They contact the maxillae anteriorly and the postorbitals posteriorly. The jugals are broken before contact with the quadratojugals.

Squamosal. In dorsal view the surface of the squamosal is crushed and somewhat fragmented. If a small, accessory ridge along the top similar to that seen in Axestemys splendida is present, it is obscured. The squamosal contacts the quadrate medially. In lateral view, the squamosal contacts the quadrate ventrally along the posterior margin of the cavum tympanum, but further contact between the two bones, as well as potential contribution of the squamosal to the antrum postoticum, is obscured.

Vomer. Pieces of the vomer are present, including at least one fragment that contacts the parietals posterolaterally.

Palatine. In ventral view, the palatines contact the vomer anteromedially and the maxillae laterally. Although the bones are separated, it appears that when the skull was complete the palatines con- tacted the pterygoids posterolaterally and the basisphenoid posteriorly. The location of the foramen palatinum posterius is obscured by the fragmentation of the palate.

Pterygoid. The pterygoids are large bones that floor the fossa temporalis inferior. They extend from anterior contact with the maxillae to posterior contact with the quadrates. They contact the palatines anteromedially, the basisphenoid posteromedially, and probably contacted the basioccipital posteromedially, although the latter contact is uncertain. The foramen posterius canalis carotici interni is surrounded by the pterygoids. Reconstructing its original position in relation to other skull features indicates that the foramen posterius canalis carotici interni were positioned posteriorly in palatal view, ventral to the basioccipital tubercule. The posterior view is deformed due to crushing, but the posterior margin of the skull made up by the opisthotic indicates that the foramen jugulare posterius is confluent with the fenestra postotica.

Basisphenoid. The basisphenoid is completely preserved, although it has broken away from most other bones along the sutures. It is bluntly triangular, with a long interdigitated posterior suture with the basioccipital. It contacted the pterygoids laterally and probably the parietals anteriorly.

Prootic. In dorsal view, the prootic forms approximately one-third of the processus trochlearis oticum. It contacts the parietal medially, the quadrate laterally, and the supraoccipital and opisthotic posteriorly. The foramen stapedio-temporale lies between the prootic and the quadrate.

Opisthotic. In dorsal view, the opisthotic contacts the prootic anteriorly, the quadrate anterolaterally, and the supraoccipital medially. It makes up part of the posterior margin of the skull. The opisthotic probably did not participate in any subdivision of the fenestra postotica (see above).

Quadrate. In dorsal view, the quadrate is visible in the fossa temporalis superior and contacts the squamosal laterally, the prootic anteromedially, and the opisthotic posteromedially. It forms the lateral extent of the processus trochlearis oticum and makes up about half of the wall of the stapediotemporal foramen. In lateral view, the quadrate forms most of the cavum tympani. Because the cavum tympani is crushed and distorted both dorsoventrally and anteroposteriorly, the contact between the quadrate and the squamosal within the cavum tympani is unclear. 
Basioccipital. The basioccipital forms the ventral part of the occipital condyle. The bones of the occipital condyle are not fused. The basioccipital is broken into two pieces. The anterior fragment contacts the basisphenoid anteriorly along an interdigitated suture. Two basioccipital tubercules are partially preserved. The exoccipitals prevent the basioccipital from participating in the foramen magnum.

Exoccipital. The exoccipitals form the dorsal twothirds of the occipital condyle. They contact the basioccipital ventrally along the occipital condyle.

Supraoccipital. Although flattened, the part of the crista supraoccipitalis that remains is high. The preserved part of the supraoccipital is T-shaped and contributes to much of the crista supraoccipitalis posteriorly, while the parietal forms the anterior part of the crista supraoccipitalis. In posterior view, the supraoccipital forms the dorsal margin of the foramen magnum.

Mandible. Figure 15. The mandible found in the Fort Union Formation is mostly complete, although it is broken into two pieces roughly along the midline. A partial dentary found in the Denver Formation preserves the anterior margin of the mandible and part of the triturating surface. The holotype UMMP 27029 preserves a small fragment of the right dentary pocket and the coronoid process, as well as the left half of the mandible.

Dentary. In dorsal view, the dentary has a short, rounded anterior margin. It lacks a symphyseal ridge. The lingual and labial ridges are both present and pronounced. The triturating surface is broad and rugose. Anteriorly, it extends past the anterior margin of the rest of the dentary, forming a dorsal lip. A large dentary pocket is present. In lateral view, the dentary contacts the coronoid posterodorsally and the surangular posteriorly. In medial view, the dentary contacts the coronoid posterodorsally and the prearticular posteriorly. The dentary contacts the angular along a long, interdigitated suture posteriorly, then posterodorsally along a long, straight suture.

The partial dentary (UCM 49228) found in the Denver Formation is similar to the mandible from the Fort Union Formation in having a wide, rugose triturating surface in dorsal view and a lip formed by the triturating surface on the anterior of the mandible in lateral view.

Angular. The angular covers approximately onequarter of the medial surface of the mandible. It contacts the dentary anteriorly, the prearticular dorsally, and the articular posterodorsally.
Surangular. In lateral view, the surangular contacts the dentary anteriorly and the coronoid dorsally. The foramen nervi auriculotemporalis is divided into two openings ventral to the articularis mandibularis, a smaller foramen within a larger foramen. In dorsal view, the surangular forms about half of the area articularis mandibularis.

Coronoid. The coronoid process is high, with proportions more similar to Axestemys splendida than to Gilmoremys lancensis. In medial view the coronoid contacts the dentary anteroventrally and the prearticular posteroventrally.

Articular. The articular is partially preserved at the posteriomedial margin of the mandible. In dorsal view it forms approximately half of the area articularis mandibularis and contacts the surangular laterally. In medial view it forms the posterior margin of the mandible. The articular contacts the angular ventrally and the prearticular anteriorly.

Prearticular. In medial view, the prearticular contacts the coronoid anteriorly and the articular posteriorly. Along a long ventral suture the prearticular contacts the dentary anteroventrally and the angular posteroventrally.

Carapace. Figure 16. Most of the anterior half of the carapace is preserved in UMMP 27029 including the nuchal, preneural, neurals 1 and 2 , and most of the first through fifth costals. The length at the midline from the anterior margin of the carapace to the anterior margin of the fifth costals is 31 $\mathrm{cm}$. The length of the carapace when complete is estimated to be approximately $64 \mathrm{~cm}$. The outline of the preserved carapace is subrectangular. The anterior margin is slightly emarginated medially. The lateral margins may have been straight or scalloped-not enough is preserved to be sure. Unlike Hutchemys arctochelys the carapace has no kind of waist or significant emargination, and the visceral side of the carapace is smooth.

A callosity covers most of the carapace bones, with the exceptions of the ends of the ribs that extend from the carapacial margin, and the anterior and lateral parts of the nuchal. The medial part of the callosity is sculptured in a pattern of thin ridges that form subparallel ridges laterally and intersect to form broad, flat-bottomed, circular pits medially. At the lateral-most edges of sculpturing, the ridges may break up into smaller ridges or into a series of small, irregular pustules. A smooth band as wide as $64 \mathrm{~mm}$ makes up the lateral margin of the callosity. The costal fragments from the Denver Formation, such as DMNH 44622 and 44623 also preserve the unsculptured band around the border 
of the callosity. The pattern is similar to that of Axestemys cerevisia.

Nuchal. The nuchal is 4.3 times wider than long and lacks both posterior costiform processes and a prenuchal. The anterior margin is slightly emarginated medially, but no more than the extent seen in Axestemys splendida. The first thoracic vertebra is situated in the middle of the nuchal. Suprascapular fontanelles are absent, and the suture between the nuchal, first costals, and prenuchal is complete. The ribs of the first costals overlap the lateral part of the suture between the nuchal and first costals.

Neurals. A preneural (neural 1 in the terminology of Meylan, 1987) and two neurals are preserved in UMMP 27029. The preneural is wider and shorter than the other neurals. Neurals 1-2 are hexagonal with short posterolateral sides. The isolated neural found in the Denver Formation (DMNH 44623) is similar in size and shape to neurals 1-2 in UMMP 27029; the former is $60 \mathrm{~mm}$ long and the latter is $58 \mathrm{~mm}$ long.

Costals. UMMP 27029 preserves the first five costals, although the third through fifth are incomplete. The distal edge of the costals is rounded. The free rib ends extend as much as $5.5 \mathrm{~cm}$, but when complete could have extended farther. The distal margin of the first costals is about the same length as the medial margin.

Plastron. Figures 16, 17. The plastron has four callosities: one on each hyoplastron and hypoplastron and one on each xiphiplastron.

Epiplastron. The epiplastra are bent at the point of anterior-most contact with the entoplastron, making them J-shaped. The part of the epiplastron anterior to the entoplastron is short, 0.24 times the width of the hypoplastron.

Entoplastron. The entoplastron is V-shaped, with an approximately 90 degree angle between the two arms of the $\mathrm{V}$. Where the arms of the entoplastron meet, two small processes extend from the anterior edge of the bone with a small crescent-shaped gap between them. Unlike plastomenids or extant Apalone spp., the entoplastron is not sutured to the hyoplastron, nor is there a hyoplastral shoulder developed to accommodate extensive contact between the hyoplastron and entoplastron.

Hyoplastron and Hypoplastron. The hyoplastron and hypoplastron are connected by a suture, but do not fuse. The callosity on the hyoplastron and hypoplastron is almost entirely devoid of sculpturing. Small pustules and ridges are present on the lateral-most sections of UMMP 27029, as well as faint sculpturing of a similar pattern on the hyoplastral bridge of DMNH 44623. The callosity covers most of the hyoplastron and hypoplastron, excluding the lateral and medial processes. In UMMP 27029 , the callosity does not reach the lateral margin of the hyoplastron and hypoplastron, and in no specimen does it extend past the lateral processes. The hyoplastral-hypoplastral bridge is short, just over one-quarter of the maximum hypoplastron width. There is no extensive midline contact between the two hyoplastra and hypoplastra.

The hyoplastra have a single lateral process and 3-5 medial processes. The hypoplastra have two lateral processes. Medial hypoplastral processes consist of eight small processes distributed evenly along the posteromedial margin of the hypoplastron, followed by two larger posteromedial processes that articulate with the xiphiplastron.

Xiphiplastron. The xiphiplastra are subtriangular, with a brief emargination at the lateral edge (UMMP 27029, Figure 16) that disappears as the callosity covering the xiphiplastron becomes more extensive (PTRM 6030.05 and PTRM 6030.06, Figure 17).

The callosity is covered by a sculpture pattern that consists of thin, uneven ridges that occasionally break down into shorter ridges and pustules. This pattern is similar to that seen in lateral sections of the carapace. At the hypoplastral-xiphiplastral contact, the xiphiplastron is lateral-most. The xiphiplastra meet narrowly at the midline, although there is no suture between the two xiphiplastra.

Non-shell Postcranials. Figures 7 and 18. Cervical vertebrae, pieces of both pectoral and pelvic girdles, and several appendicular elements are preserved in specimens from all three formations. The appendicular elements are indistinguishable from those of Apalone spp. except for their large size. For example, ungual phalanges are as large as $5.8 \mathrm{~cm}$ long (DMNH 44622), at least 4.1 times the length of an ungual phalanx of an Apalone ferox specimen with a $16.2 \mathrm{~cm}$ carapace (YPM R 10574).

Cervical Vertebrae. UMMP 27029 preserves the $7^{\text {th }}$ and $8^{\text {th }}$ cervical vertebrae, as well as three other vertebrae of unknown number. PTRM 5350.21 is a $7^{\text {th }}$ vertebra, and PTRM 5350.22, PTRM 5350.30, and PTRM 5350.108 are three vertebrae of uncertain order. The ventral surface of the $8^{\text {th }}$ vertebra has a small posterior keel. Although the dorsal surfaces of three of the cervical vertebrae of UMMP 27029 are incomplete, dorsal processes are present on the posterior surface 
of the vertebrae (Figure 7.5-7.7). Small dorsal processes are also present on PTRM 5350.21 and PTRM 5350.30 (Figure 7.2, 7.4).

Pectoral Girdle. The coracoid is the longest of the three pectoral processes. The acromion process and the scapula are approximately the same length. The angle between the acromion process and the scapula is nearly 90 degrees, and the angle between the acromion process and the coracoid is much less-20 degrees at most.

Pelvic Girdle. The anterior end of the pubis is incomplete in all specimens, but the ischium and ilium are entirely preserved in PTRM 5350.3 and UMMP 27029. There is no division of the obturator fenestra. The ilia curve posteriorly, but not medially. The ischia do not extend into the obturator fenestra, but a distinct, medially curving metischial process is present outside of the obturator fenestra.

\section{Remarks}

Although 12 taxa of trionychids already are named from Puercan-Tiffanian specimens, Axestemys montinsana differs significantly from all of them. Diagnostic characters include traditionally recognized characters, such as the presence of a preneural, the lack of significant medial plastral contact, lack of an anterior hyoplastral shoulder, and nuchal length:width ratio, as well as apomorphies found in other Axestemys taxa, such as the lack of sculpturing on the hyoplastral and hypoplastral callosity, the small double anterior processes on the entoplastron, the single lateral hyoplastral process, relatively long, free rib ends, very large size, and the band of unsculptured callosity around the border of the carapace.

In particular, Axestemys montinsana differs from the previously named Puercan taxon "Axestemys" puercensis in its much larger size, lack of fontanelles, smooth band of unsculptured callosity around the carapace, and unsculptured hyoplastra and hypoplastra. Previously, the smooth band on the border of the carapace was considered a juvenile feature (Hutchison and Holroyd, 2003), and size and the presences of fontanelles previously were considered juvenile features (Hutchison and Holroyd, 2003; Meylan, 1987). Therefore, the possibility that Axestemys montinsana represent adult specimens of "Axestemys" puercensis should be addressed.

The fontanelles seen in "Axestemys" puercensis and some other Axestemys taxa are different from the fontanelles seen in extant juvenile trionychids (see Systematics section of Results for further discussion), and often are retained in very large, presumably adult extinct trionychids, indicating that their presence is not related to ontogeny. Furthermore, it is unclear why the hyoplastron and hypoplastron would lose sculpturing almost entirely during growth while the sculpturing on the xiphiplastra remains intact. It is more likely that, as in Oliveremys uintaensis, the lack of sculpturing on certain plastral elements is a useful feature not related to ontogeny (Vitek, 2011). These character differences between "Axestemys" puercensis and Axestemys montinsana are best explained as interspecific differences rather than ontogenetic variation.

The Denver Formation skull fragments described here and elsewhere (Hutchison and Holroyd, 2003) and included in this taxon were considered synonymous with Conchochelys admiribalis Hay, 1905 based on their similar age, large size, deep maxillae, shape of the triturating surface, and short snout (Hutchison and Holroyd, 2003). However, comparison of Conchochelys admiribalis with the more complete skull of UMMP 27029 shows that the two skulls are different. Conchochelys admiribalis has a much narrower snout, smaller orbits, and a secondary palate in which the openings of the choanae are placed more posteriorly in ventral view. Most of the sutures on Conchochelys admiribalis are not visible, making more detailed comparison difficult, but from general skull shape it is clear that Axestemys montinsana and Conchochelys admiribalis are not synonymous.

\section{RESULTS}

\section{Phylogenetic Analysis}

Parsimony analysis produced 315 most parsimonious trees of 288 steps. A strict consensus of all 315 trees (Figure 1.1) recovered Plastomenidae, Cyclanorbinae, and Apalone as well-resolved clades, but otherwise found poor resolution within Trionychinae. When the analysis recovered clades such as Aspideretes and Pelodiscini, relationships within the clades remained unresolved. Some otherwise well-established clades such as Aspideretini and Rafetus were not recovered at all. Relationships within Plastomenidae are identical to those recovered by Joyce and Lyson (2011), and relationships within Apalone are identical to the results of both morphological and molecular studies (Meylan, 1987; Engstrom et al., 2004).

In the strict consensus tree, Axestemys was recovered as a monophyletic group sister to Aspideretoides foveatus. Within Axestemys, Axestemys byssina and Axestemys quinni are the most 
derived sister taxa. They, in turn, are sister to Axestemys cerevisia, which formed a clade sister to Axestemys montinsana, and this group of species formed a clade sister to Axestemys splendida.

As a result of the Adams consensus tree resulting from the initial parsimony analysis of the complete dataset, Nilssonia formosa was experimentally removed from the dataset, and parsimony analysis was performed again. The analysis resulted in 52 most parsimonious trees of 283 steps $(\mathrm{Cl}=.4134 ; \mathrm{RI}=0.6201)$. In a strict consensus tree, resolution increased within Aspideretes and Pelodiscini, but the clade composed of Rafetus, Apalone, Axestemys, Aspideretoides foveatus, Aspideretoides allani, Oliveremys uintaensis, and "Trionyx" egregius remained poorly resolved.

Other researchers have also found the placement of Nilssonia formosa problematic. Although Nilssonia formosa was recovered as the sister group to the four species of Aspideretes in a morphological analysis (Meylan, 1987), the combined morphological and molecular analysis by Engstrom et al. (2004) placed Nilssonia formosa, albeit with weak support and poor resolution, within Aspideretes. The lack of resolution within Aspideretini-the clade composed of Aspideretes and Nilssonia - was notable, given how well supported the rest of the tree was. Furthermore, Praschag et al. (2007) performed a phylogenetic analysis focusing on molecular data from Aspideretini and could not find well-resolved relationships within the clade. Therefore, although it is clear that Nilssonia formosa and Aspideretes are closely related, all datasets used thus far provide conflicting information concerning the exact nature of the relationship.

An Adams tree consensus of the 52 trees resulting from parsimony analysis of the dataset minus Nilssonia formosa resulted in resolution for every single taxon except "Trionyx" egregius. "Trionyx" egregius is a poorly known extinct taxon from the Eocene. It is known only from a single described carapace (Hay, 1908), which is identical to carapaces of Oliveremys uintaensis except for a single character.Oliveremys uintaensis has a 4-to1 nuchal width:length ratio, while "Trionyx" egregious has a 3-to-1 ratio. A previous analysis supported the designation of the two as separate taxa (Vitek, 2011). "Trionyx" egregius was experimentally removed from the dataset, and the analysis was performed again. Parsimony analysis of the morphological dataset minus Nilssonia formosa and "Trionyx" egregius produced a single most parsimonious tree of 283 steps $(\mathrm{Cl}=0.4134, \mathrm{RI}=$ 0.6175 ; Figure 1.2). Few clades had high bootstrap support, those being Plastomenus/Hutchemys, Chitra/Pelochelys, Rafetus, and Apalone mutica/ Apalone spinifera.

\section{Systematics}

Phylogenetic analysis supports the hypothesis that Axestemys byssina, the type species of Axestemys, is part of a monophyletic group of giant fossil North American trionychids. This clade contains five species, discussed below.

Axestemys byssina shares with Axestemys splendida-the oldest and phylogenetically most basal representative of Axestemys - the plesiomorphic characters of a nuchal at least four times wider than long, a preneural, a single lateral hyoplastral process, the presence of four plastral callosities, and a short hyoplastral-hypoplastral bridge. They and the other members of Axestemys share the local apomorphy of having an extremely large size, with carapaces at least $600 \mathrm{~mm}$ in length. A distinct category of giant trionychids of this size was found within extant taxa (Pritchard, 2001) and includes Rafetus swinhoei, Chitra chitra, Chitra indica, Pelochelys bibroni, and Pelochelys cantorii. Pelochelys and Chitra are considered sister taxa, and therefore it is likely that the distribution of gigantism in modern trionychids is the result of independent evolution of gigantic size in two lineages. In addition, both the skull fragments referred to Axestemys byssina and all skulls referred to Axestemys splendida (with the exception of MRF 266) have sculpturing on the surface of the skull roof, a character not found in any extant trionychids or extinct North American trionychids that are not a part of Axestemys. These two apomorphies support the inclusion of Axestemys splendida within Axestemys and help to diagnose the clade as a whole. My analysis yields no autapomorphies for Axestemys splendida within Axestemys, although its unique combination of characters support its designation as a separate species.

Axestemys montinsana can be included within Axestemys based on a sculptured skull roof and large adult carapace size. Furthermore, Axestemys montinsana and most other more derived members of Axestemys have a callosified but unsculptured hyoplastron and hypoplastron and a wide unsculptured band on the border of the callosity covering the carapace. Most trionychids have some sort of smooth border on the carapace, but these are usually no more than a few millimeters wide. The smooth border on the carapace of Axestemys montinsana and other Axestemys taxa is several 


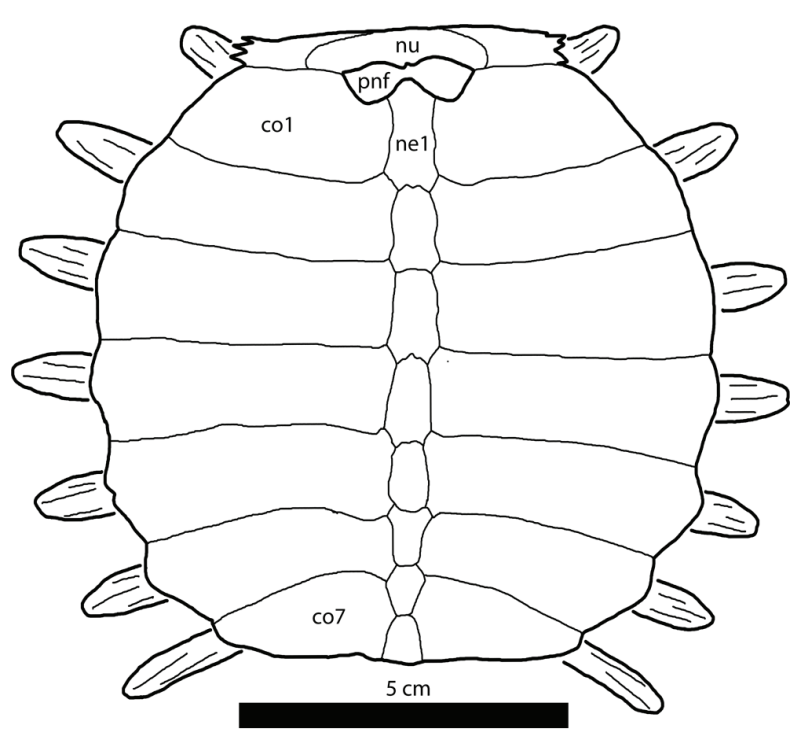

FIGURE 19. Illustration of YPM R 10890, carapace of a juvenile Apalone mutica.

centimeters-an order of magnitude wider. Axestemys montinsana, Axestemys cerevisia, and Axestemys byssina also share short twin anterior entoplastral processes. Axestemys quinni does not have a preserved plastron, and therefore its shape is unclear.

Only Axestemys splendida and Axestemys montinsana have reasonably complete skulls and mandibles. They are similar in many regards, with blunt and deep maxillae, large postorbitals, contact between the basisphenoid and palatines, a parietal that makes up more than $20 \%$ of the processus trochlearis oticum, a weakly emarginated dorsolateral edge of the apertura narium externa, high crista supraoccipitalis and coronoid processes, wide and rugose triturating surfaces, and broad dentary pockets.

Axestemys cerevisia lacks a skull, but it can be included in Axestemys based on having the largest known carapace out of all five species and a lack of sculpturing on the hyoplastral-hypoplastral callosity. Axestemys cerevisia and all other more derived members of Axestemys have suprascapular fontanelles.

Using the presence of suprascapular fontanelles to diagnose extinct taxa is hazardous because the presence of fontanelles is generally an ontogenetically variable character. Many juvenile trionychids have a loosely attached nuchal and large suprascapular fontanelles. During growth, the nuchal usually becomes more strongly sutured to the rest of the carapace and the fontanelles close. In the past, the presence of suprascapular fonta- nelles in large carapaces has been used to justify the character as diagnostic with the argument that if the carapace is large, then the individual had probably already reached adulthood and the suprascapular fontanelles would remain open throughout life (Gardner and Russell, 1994). However, without a clear growth series in fossil trionychids and a wide range of adult sizes in extant trionychids (Meylan, 1987; Pritchard, 2001) it is difficult to quantitatively decide when a carapace is 'big enough' to be considered an adult.

Comparison of the fontanelles in Axestemys with fontanelles in juvenile extant trionychids show that it is irrelevant whether or not the carapaces referred to Axestemys represent juveniles or adults. The nuchal suture pattern of Axestemys and the pattern in extant taxa with suprascapular fontanelles such as Pelodiscus sinensis and Apalone spinifera are different. In extant trionychids such as Apalone mutica (e.g., YPM R 10890, Figure 19) the lateral edge of the nuchal sutures to the anterolateral edge of the first costals before the nuchal divides the suprascapular fontanelles to contact the neural, preneural, and/or first costals medially. In contrast, the large suprascapular fontanelles of Axestemys cerevisia and Axestemys quinni show that the nuchals of those taxa sutured to the preneurals and, in some cases, the anteromedial edge of the first costals between the two fontanelles, before the nuchals sutured to the anterolateral edge of the first costals, if they formed a suture there at all. As far as is known, this nuchal suture pattern is unique to Axestemys and "Axestemys" puercensis.

Although the only specimen of Axestemys quinni (Figure 20) lacks a skull, plastron, and nonshell postcranial elements, it can be referred to Axestemys based on its gigantic size and the presence of large suprascapular fontanelles, which prevent contact between the nuchal and first costals. It is unclear whether the large type of fontanelles was derived twice in Axestemys quinni and Axestemys cerevisia, or whether it was derived once in the common ancestor of Axestemys byssina, Axestemys quinni, and Axestemys cerevisia and subsequently lost in Axestemys byssina. Axestemys byssina and Axestemys quinni, the two most phylogenetically derived members of Axestemys, share the character of extremely reduced eighth costals. A cladogram of the character transitions discussed above is shown in Figure 21. Axestemys quinni has been considered a member of Axestemys for several years already, after Hutchison and Holroyd 

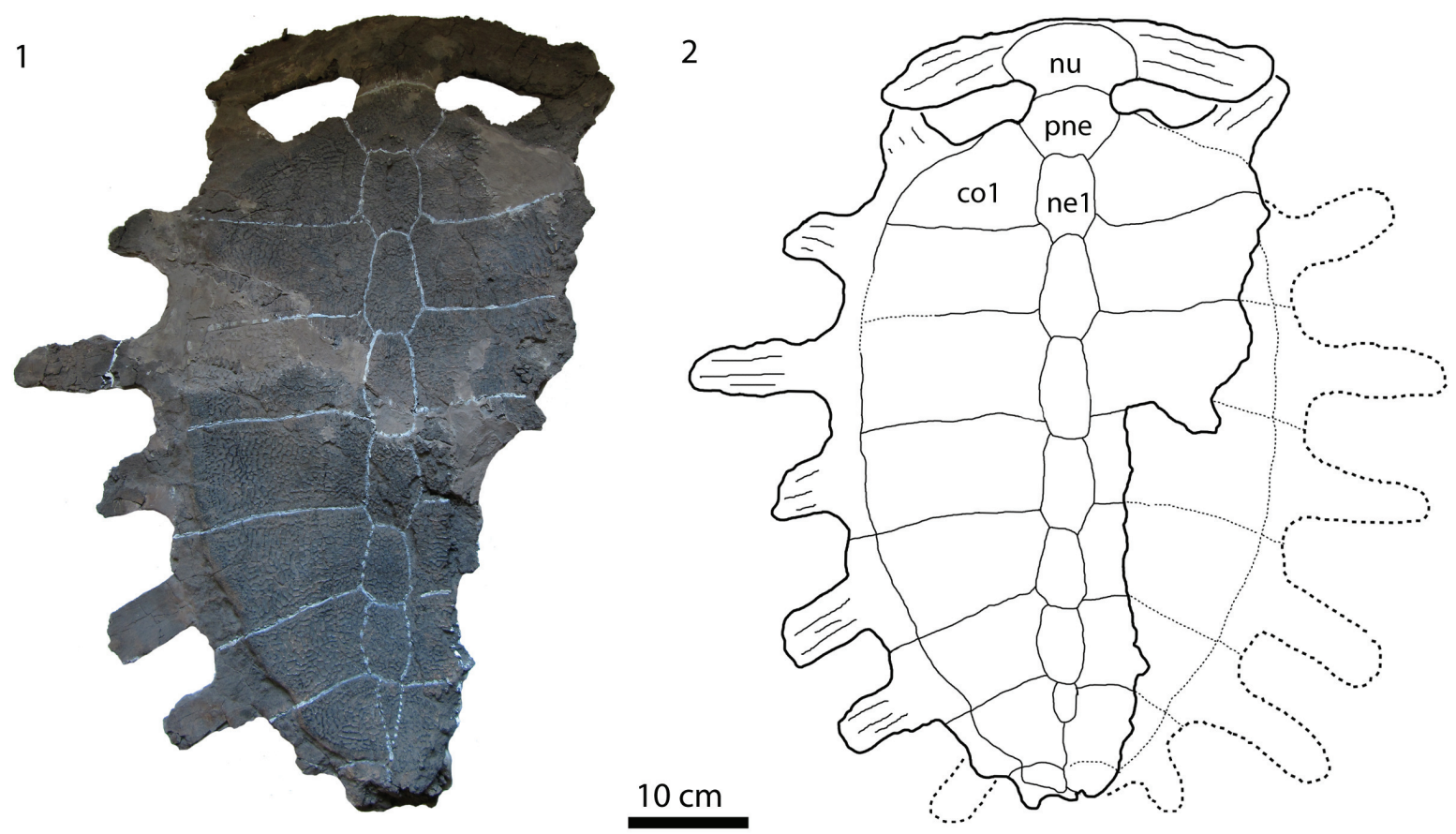

FIGURE 20. FMNH P 26641, holotype of Axestemys quinni from the Paleocene De Beque Formation of Colorado. A, Photograph and B, illustration of carapace. Abbreviations: $c o=$ costal, ne $=$ neural, nu $=$ nuchal, pne $=$ preneural.

(2003) synonymized its original generic name Paleotrionyx with Axestemys.

One other giant North American taxon with unsculptured xiphiplastral and hyoplastral- hypoplastral callosities is named. Chkhikhvadze (2008) named Eugenichelys robertemryi based on specimen USNM 12589, a partial plastron as well as some skull fragments. He proposed that $E$. robertemryi differed from Axestemys in that the former came from older sediments. The two holotype specimens come from the Wasatch Formation and Bridger Formation, respectively. It is not uncommon for the ranges of fossil trionychid taxa to extend across ages as long or longer than the Wasatchian-Bridgerian, and, without any morphological differences, an age difference this small is not enough to justify a separate taxon. Examination of USNM 12589 shows no difference between this specimen and the holotype material of Axestemys byssina or any other material referred to this taxon from both the Wasatch and Bridger Formations. Axestemys byssina was named before Eugenichelys robertemryi and therefore has priority. For these reasons, E. robertemryi is synonymized with Axestemys byssina.

"Axestemys" puercensis was historically referred to the same genus as Axestemys quinni and Axestemys cerevisia based on its large suprascapular fontanelles, which separate the nuchal from the first costals (Schmidt, 1945; Hutchison and Holroyd, 2003). It shares other characteristics with Axestemys such as a preneural, 7-8 neurals, and long rib ends extending from the edge of the carapace (Hutchison and Holroyd, 2003). Long rib ends previously were considered characteristic of Axestemys (Hutchison and Holroyd, 2003), and there is evidence to suggest that retention of long rib ends at large sizes is a derived feature (Gardner and Russell, 1994). However, long rib ends are also a juvenile feature of trionychids, and "Axestemys" puercensis is much smaller than all other species of Axestemys (carapace length $330 \mathrm{~mm}$ ). Therefore, use of long rib ends in adult specimens as evidence that "Axestemys" puercensis is a member of Axestemys may be conflating a possibly species-diagnostic character with an ontogenetically variable character.

It is possible that the holotype specimen of "Axestemys" puercensis represents a juvenile, and that adult individuals of the taxon grew large enough to be considered giant. As it stands now, it is difficult to recognize juvenile specimens of Axestemys if they lack the more derived characters of the clade. However, the only described giant 


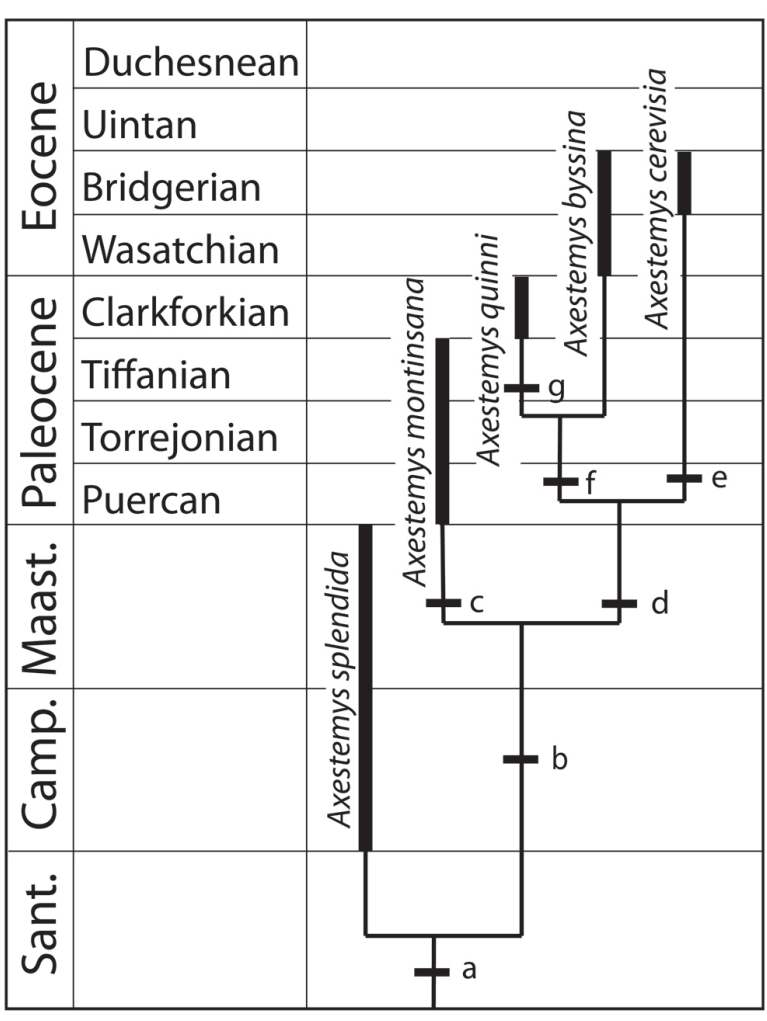

FIGURE 21. The stratigraphic distribution of taxa discussed in the text. Thin lines indicate phylogenetic relationships only and do not indicate divergence date estimates. Letters indicate character transitions. Key: a = carapace length at least $60 \mathrm{~cm}$, sculpturing on the skull roof; $b=$ smooth hyoplastral and hypoplastral callosity, smooth border around carapace callosity; c = dorsal processes on the cervical vertebrae; $d=$ suprascapular fontanelles; e = loss of xiphiplastral callosity, strong reduction of hyoplastral and hypoplastral callosity; $f=$ reduced eighth costals, smooth xiphiplastral callosity; $\mathrm{g}=$ loss of smooth band around carapace callosity.

Puercan trionychid specimens differ from "Axestemys" puercensis in several characters, including smooth hyoplastral and hypoplastral callosities, the absence of suprascapular fontanelles, and a wide, smooth band on the lateral border of the carapace. Those specimens were referred to Axestemys montinsana, and no intermediate specimens of the same age are reported that would suggest an ontogenetic transition between the two taxa. Furthermore, there is no phylogenetic support for the inclusion of "Axestemys" puercensis within Axestemys. Without evidence that "Axestemys" puercensis reached gigantic size or developed other characters found in other species of Axestemys, the presence of open suprascapular fontanelles is not sufficient evidence to justify referring "Axestemys" puercensis to Axestemys.

Several shell and skull fragments from a large trionychid were referred to "Axestemys" puercensis (Hutchison and Holroyd, 2003). On the basis of those fragments, the fact that they were found in the same rock unit as the skull-only taxon Conchochelys admiribalis, and the similarities between the skull fragments and Conchochelys admiribalis, the authors synonymized Conchochelys admiribalis and "Axestemys" puercensis and referred them both to Axestemys. New material described in this study indicates that these skull and shell fragments belong to Axestemys montinsana rather than to "Axestemys" puercensis, and that the skull of Axestemys montinsana differs in several ways from Conchochelys admiribalis. Without these fragments, there is no evidence to suggest that "Axestemys" puercensis and Conchochelys admiribalis are synonymous, or that Conchochelys admiribalis should be included in Axestemys.

\section{DISCUSSION}

The idea that Axestemys can be identified as a group of trionychids with generally paedomorphic shells, based on long, free rib-ends, the presence of suprascapular fontanelles, and a general reduction of carapacial and plastral callosities at large body sizes was proposed in the most recent review of the clade (Hutchison and Holroyd, 2003). Trionychids as a whole already are considered to have some paedomorphic characters. Of those, some characters such as the loss of peripherals are generally agreed to be due to developmental truncation (Meylan, 1987; Kordikova, 2000). Other characters such as the occasional appearance of a pair of costals anterior to the first costals, the development of a preneural, and the lack of development of a bridge between the carapace and plastron, were attributed to paedomorphosis but still lack developmental evidence (Kordikova, 2000). Pending such evidence, paedomorphosis does not appear to be an overwhelming factor in trionychid evolution (Meylan, 1987).

Similarly, in Axestemys some of the characters seen in some of the species can be explained through paedomorphism. These characters are the relatively long rib-ends seen in Axestemys quinni and Axestemys cerevisia, the restriction of the hyoplastral and hypoplastral callosity and the absence of a xiphiplastral callosity in Axestemys cerevisia, and the reduced carapacial callosity in Axestemys quinni. However, these characters are not distributed throughout all of the taxa in Axestemys. The 
large, open suprascapular fontanelles in Axestemys cerevisia and Axestemys quinni are not homologous to the suprascapular fontanelles seen in extant juvenile trionychids, and without a growth series for fossil trionychids with the Axestemys quinni-type nuchal attachment, it is unclear how this character is related to trionychid development. Other characters, such as smooth plastral callosities and a smooth carapacial border, are not clearly related to paedomorphosis. Therefore, while it is possible that paedomorphosis played a role in the evolution of more derived taxa of Axestemys, it does not appear to be the principal factor influencing the evolution of Axestemys.

The systematics of Axestemys indicate that, contrary to historical precedent, it is not possible to diagnose Axestemys based solely on the characters exemplified by the type species Axestemys byssina or more derived taxa such as Axestemys cerevisia. Traditional characters used to diagnose Axestemys, such as large suprascapular fontanelles and smooth plastral callosities, are found in other non-Axestemys fossil taxa such as Aspideretoides allani, "Axestemys" puercensis, and Oliveremys uintaensis. With the exception of the presence of sculpturing on the skull roof, no characters that could diagnose Axestemys are found throughout the entire group and nowhere else within trionychids. Gigantic size is an unsuitable character in the absence of other characters because it is found in other non-Axestemys taxa such as Rafetus swinhoei, Chitra chitra, Chitra indica, Pelochelys bibroni, and Pelochelys cantorii, and the Cretaceous Asian "Trionyx" kansaiensis (Pritchard, 2001; Vitek and Danilov, 2010), and therefore gigantism among these turtles must have evolved at least two other times beside that in Axestemys.

\section{CONCLUSIONS}

Rather than think of Axestemys as a group of paedomorphic turtles with a remarkable morphology, as was previously supposed, Axestemys is better thought of as a wholly extinct monophyletic side branch of gigantic trionychids. Although the position of the clade is still potentially labile within Trionychinae, the current hypothesis is that they, along with a grade of other trionychids, form a sister group to Apalonina sensu Meylan, 1987. This analysis does not support the hypothesis that Axestemys belongs within Rafetus, or as part of a clade Rafetini (Chkhikvadze, 2000). The stratigraphic range of Axestemys is longer than previ- ously supposed, now extending from the Campanian to the Bridgerian (Figure 21).

The monophyly of Axestemys suggests the possibility that gigantism developed once in North American trionychids, and that gigantism was conserved in a single lineage for approximately 24 million years. However, until Conchochelys admiribalis-currently represented by a single large skull that may have belonged to a gigantic shell-is more fully understood, this hypothesis leaves some taxa unaccounted for.

Multiple factors could have influenced the evolution of giant fossil soft-shell turtles in North America. The first is climate. Trionychids, as poikilotherms, have a limit on their maximum body size imposed by the mean annual temperature of their environment (Head et al., 2009; Head, 2010). Warmer temperatures allow larger body size. For example, Recent trionychid species that reach gigantic sizes are restricted to the tropics (Pritchard, 2001; Ernst and Barbour, 1989). The significantly warmer global climate 70-46 million years ago would have allowed a larger body size and would have made it possible for trionychids with meter-long shells to live in Wyoming.

The second factor is diversity and sympatry of trionychid taxa. Where multiple taxa are broadly sympatric, they develop significant size differences. This size divergence is hypothesized to be a characteristic of ecological niche partitioning in sympatric turtles (Pritchard, 2001). Areas with higher diversity may encourage size divergence and therefore gigantism. Today, Java, the area with the highest sympatry, includes one small, one large, and two giant trionychids. There, one of the giant species is hypothesized to avoid competition with the second taxa by inhabiting estuarine environments (Pritchard, 2001). High diversity in western North America might have also encouraged the evolution of gigantic trionychids.

These two factors are in no way mutually exclusive. The island of Java, Indonesia, is both tropical and the area of highest diversity of Trionychidae on Earth, with four species living in broad sympatry. Similarly, Western North America had a warm climate from the Maastrichtian through the Bridgerian Eocene, and in at least some periods had high trionychid diversity. For example, the Campanian Judith River Formation has five species of trionychid: Aspideretoides foveatus, "Aspideretoides" allani, Axestemys splendida, "Apalone" latus, and ?Plastomeninae gen. et sp. indet. (Brinkman, 2005). 
Recent attempts to study fossil trionychid diversity in North America were complicated by a hyperinflated number of species reported based on fragmentary and undiagnostic material (Gaffney, 1979; Joyce et al., 2009). For example, at least 23 species have been named from the Bridger Formation alone. Of those, only four species have recently been reviewed and included in phylogenetic analyses that supports their designation as distinct and valid (Plastomenus thomasii, Oliveremys uintaensis, Axestemys byssina, and Axestemys cerevisia; Joyce and Lyson, 2010; Vitek, 2011; this study). Their bony carapaces range from 21 to $97 \mathrm{~cm}$ long (Hay, 1908; Gaffney, 1979).

However, even if all of the other 19 species are later found to be invalid or synonymous with these four, the Bridger Formation trionychid fauna is still more diverse than the modern North American trionychid fauna and at least as diverse as Java, where four trionychid species with bony carapaces ranging from 22 to $74 \mathrm{~cm}$ are found in broad sympatry (Pritchard, 2001). Based on this work, it is hypothesized that further study of North American trionychids, such as those in the Bridger Formation, will reveal a diversity and disparity higher than any place on earth today. Although much work remains in the project of revising the systematics of North American Cretaceous-Eocene fossil trionychids, future work regarding the diversity of taxaand the wide range of size that seems to come with it-might be best compared to modern diversity in localities like Java, rather than the modern North American trionychid fauna.

\section{ACKNOWLEDGMENTS}

Thanks to the MRF volunteers and staff for finding and preparing Hell Creek Formation specimens; to B. Roach, M. Fox, and V. Heisey, for preparation work on MRF and UMMP specimens; to $E$. Schachner for her illustration of MRF 266; to curators and staff of the American Museum of Natural History, Denver Museum of Nature and Science, Field Museum of Natural History, Marmarth Research Foundation, Pioneer Trails Regional Museum, National Museum of Natural History, University of Colorado Museum, and the University of Wyoming for access to specimens in their care; to D. Krause for information regarding UMMP 27029; to J. Gauthier, T. Lyson, and W. Joyce for discussion and helpful comments that improved the manuscript; to C. Bell and two anonymous reviewers for comments that improved the manuscript; to the Yale College Dean's Research Fellowship in the
Science for support for fieldwork to collect specimens with MRF.

\section{REFERENCES}

Batsch, A.J.G.C. 1788. Versuch einer Anleitung, zur Kenntniß und Geschichte der Thiere und Mineralien. Akademische Buchhandlung, Jena.

Bercovici, A., Pearson, D., Nichols, D., and Wood, J. 2009. Biostratigraphy of selected K/T boundary sections in southwestern North Dakota, USA: toward a refinement of palynological identification criteria. Cretaceous Research, 30:632-658.

Brinkman, D.B. 2003. A review of nonmarine turtles from the Late Cretaceous of Alberta. Canadian Journal of Earth Science, 40:557-571.

Brinkman, D.B. 2005. Turtles: diversity, paleoecology and distribution, p. 202-220. In Currie, P.J. and Koppelhus, E.B. (eds.), Dinosaur Provincial Park: A Spectacular Ancient Ecosystem Revealed. Indiana University Press, Bloomington.

Ckhikvadze, V.M. 2000. O sistematicheskom polozheniye nekotorikh vimershikh trekhkogotnikh cherepakh Severnoi Ameriki i Azii. Trudy Tbilisskogo gosudarstvennogo pedagogicheskogo universiteta, 7:199-213. (in Russian)

Chkhikvadze, V.M. 2008. Trekhkogotniye cherepakhi (Trionychidae) Azii i Severnoi Ameriki: morfologiya, filogeniya, sistematika, terminologiya elementov karapaksa. Problemy paleobiologii, Tbilisi, 3:85-95. (in Russian)

Cope, E.D. 1868. On the origin of genera. Proceedings of the Academy of Natural Sciences of Philadelphia, 1868:242-300.

Cope, E.D. 1872. Descriptions of some new vertebrata from the Bridger Group of the Eocene. American Philosophical Society Proceedings, 8:460-465.

Cope, E.D. 1884. The Vertebrata of the Tertiary formations of the West. United States Geological Survey of the Territories, 3:1-1009.

Cuvier, G. 1825. Recherches sur les Ossements Fossiles. Paris.

Daudin, F.M. 1802. Histoire Naturelle, Générale et Particulière des Reptiles; ouvrage faisant suit à l'Histoire naturell générale et particulière, composée par Leclerc de Buffon; et rédigee par C.S. Sonnini, membre de plusieurs sociétés savantes. Vol. 2. F. Dufart, Paris.

de Broin, F. 1977. Contribution à l'étude des Chéloniens. Chéloniens continentaux du Crétacé et du Tertiaire de France. Mémoires de Muséum National d'Histoire Naturelle, Nouvelle Serié C, 38:1-366.

Duméril, A.M.C. and Bibron, G. 1835. Erpetologie general ou histoire naturelle complete des reptiles, Vol. 2. Roret, Paris.

Engstrom, T.N., Shaffer, H.B., and McCord, W.P. 2004. Multiple data sets, high homoplasy, and the phylogeny of softshell turtles (Testudines: Trionychidae). Systematic Biology, 53:693-710. 
Ernst, C.H. and Barbour, R.W. 1989. Turtles of the World. Smithsonian Institution Press, Washington, D.C.

Forskål, O. 1775. Descriptiones Animalium. Avium, amphibiorum, piscium, insectorum, vermium. Quae in itinere oriental observavit. Molleri, Hauniae.

Gaffney, E.S. 1972. An illustrated glossary of turtle skull nomenclature. American Museum Novitates, 2486:133.

Gaffney, E.S. 1979. Description of a large trionychid turtle from the Eocene Bridger Formation of Wyoming. Contributions to Geology, University of Wyoming, 17:53-57.

Gardner, J.D. 1992. Systematics of the Soft-Shelled Turtles (Family Trionychidae) from the Judith River Formation (Campanian). Unpublished MS thesis, University of Calgary, Calgary, Alberta.

Gardner, J.D. and Russell, A.P. 1994. Carapacial variation among soft-shelled turtles (Testudines: Trionychidae), and its relevance to taxonomic and systematic studies of fossil taxa. Neues Jahrbuch für Geologie und Paläontologie, Abhandlungen, 193:209-244.

Gardner, J.D., Russell, A.P., and Brinkman, D.B. 1995. Systematics and taxonomy of soft-shelled turtles (Family Trionychidae) from the Judith River Group (mid-Campanian) of North America. Canadian Journal of Earth Sciences, 32:631-643.

Gray, J.E. 1825. A synopsis of the genera of reptiles and amphibia, with a description of some new species. Annals of Philosophy, 10:193-217.

Gray, J.E. 1831. Synopsis Reptilium; or short descriptions of the species of reptiles, Part I. Cataphracta. Tortoises, crocodiles, and enaliosaurians. Treutel, Wurtz, and Co., London.

Gray, J.E. 1873. Notes on Chinese mud-tortoises (Trionychidae), with the description of a new species sent to the British Museum by Mr. Swinhoe, and observations on the male organ of this family. The Annals and Magazine of Natural History, London, Series 4, 12:156-161.

Hay, O.P. 1899. On the nomenclature of certain American fossil vertebrates. American Geologist, 24:345349.

Hay, O.P. 1905. On the skull of a new trionychid, Conchochelys admirabilis, from the Puerco beds of New Mexico. Bulletin of the American Museum of Natural History, 21:335-338.

Hay, O.P. 1908. The Fossil turtles of North America. Carnegie Institution of Washington Publication, 75:1568.

Hay, O.P. 1909. Descriptions of five new species of North American fossil turtles, four of which are new. Proceedings of the United States National Museum, 35:161-169.
Head, J.J. 2010. Climatic regulation of maximum body size in poikilothermic vertebrates: an empirical test using the Cretaceous and Paleogene record of North American trionychid turtles. Journal of Vertebrate Paleontology, 30:103A.

Head, J.J., Block, J.I., Hastings, A.K., Bourque, J.R., Cadena, E.A., Herrera, F.A., Polly, P.D., and Jaramillo, C.A. 2009. Giant boid snake from the Palaeocene neotropics reveals hotter past equatorial temperatures. Nature, 457:715-717.

Hummel, K. 1929. Die fossilen Weichschildkröten (Trionychia). Eine morphologisch-systematische und stammesgeschichtliche Studie. Geologische und Paläontologische Abhandlungen, Neue Folge, 16:359-487.

Hutchison, J.H. and Holroyd, P.A. 2003. Late Cretaceous and early Paleocene turtles of the Denver Basin. Rocky Mountain Geology, 38:121-142.

Joyce, W.G. and Lyson, T.R. 2010. A neglected lineage of North American turtles fills a major gap in the fossil record. Palaeontology, 53:241-248.

Joyce, W.G. and Lyson, T.R. 2011. New material of Gilmoremys lancensis nov. comb. (Testudines: Trionychidae) from the Hell Creek Formation and the diagnosis of plastomenid turtles. Journal of Palaeontology, 85:444-461.

Joyce, W.G., Revan, A., Lyson, T.R., and Danilov, I.G. 2009. Two new plastomenine softshell turtles from the Paleocene of Montana and Wyoming. Bulletin of the Peabody Museum of Natural History, 50:307-325.

Kordikova, E.G. 1994. About systematics of fossil trionychids in Kazakhstan. Selevinia, 2:3-8.

Kordikova, E.G. 2000. Paedomorphosis in the shell of fossil and living turtles. Neues Jahrbuch für Geologie und Paläontologie, Abhandlungen, 218:399-446.

Kuhn, O. 1964. Testudines, p. 1-299. In Westphal, A. and Junk, W., (eds.), Fossilium Catalogus I: Animalia, Pars. 107. Gravenhage.

Le Sueur, C.A. 1827. Note sur deux especes de tortues, du genre Trionyx de Geoffroy St. Hilaire. Mémoires de Muséum National d'Histoire Naturelle Paris, 15:257-268.

Leidy, J. 1856. Notices of the remains of extinct reptiles and fishes discovered by Dr. F.V. Hayden in the bad lands of the Judith River, Nebraska Territory. Proceedings of the Academy of Natural Sciences of Philadelphia, 8:72-73.

Meylan, P.A. 1987. The phylogenetic relationships of softshelled turtles (family Trionychidae). Bulletin of the American Museum of Natural History, 186:1-101.

Parks, W.A. 1933. New species of dinosaurs and turtles from the Upper Cretaceous formations of Alberta. University of Toronto Studies, Geological Series, 34:1-33. 
Praschag, P., Hundsdorfer, A.K., Reza, A.H.M.A., and Fritz, U. 2007. Genetic evidence for wild-living Aspideretes nigricans and a molecular phylogeny of South Asian softshell turtles (Reptilia: Trionychidae: Aspideretes, Nilssonia). Zoologica Scripta, 36:301310.

Pritchard, P.C.H. 2001. Observations on body size, sympatry, and niche divergence in softshell turtles (Trionychidae). Chelonian Conservation and Biology, 4:527.

Schmidt, K.P. 1945. A new turtle from the Paleocene of Colorado. Fieldiana: Geology, 10:1-4.

Scott, C.S. and Krause, D.W. 2006. Multituberculates (Mammalia, Allotheria) from the earliest Tiffanian (late Paleocene) Douglass Quarry, eastern Crazy Mountains Basin, Montana. Contributions from the Museum of Paleontology, University of Michigan, 31:211-243.
Swofford, D.L. 2003. PAUP*. Phylogenetic Analysis Using Parsimony ("and Other Methods) [computer program]. Version 4.0b10. Sunderland, MA: Sinaurer.

Vitek, N.S. and Danilov, I.G. 2010. New material and a reassessment of soft-shelled turtles (Trionychidae) from the Late Cretaceous of Middle Asia \& Kazakhstan. Journal of Vertebrate Paleontology, 30:383393.

Vitek, N.S. 2011. Insights into the taxonomy and systematics of North American Eocene soft-shelled turtles from a well-preserved specimen. Bulletin of the Peabody Museum of Natural History, 52:189-208.

Wiegmann, A.F.A. 1835. Beiträge zur Zoologie, gesammelt auf einer Reise um die Erde, von Dr. F.J.F. Meyen. Siebente Abhandlung. Amphibien. Nova Acta Academiae Caesarae Leopoldina Carolinae Germanicae Naturae Curisorum, 17:183-268.

Zangerl, R. 1969. The turtle shell, p. 311-339. In Gans, C. and Parsons, T.S. (eds.), Biology of the Reptilia Volume 1. Academic Press, London. 


\section{APPENDIX 1}

\section{LIST OF CHARACTERS}

1-77: The first 77 characters are taken directly from Vitek's (2011) analysis. This analysis is based off of the analysis of Joyce et al. (2009) with some revisions to character wording and scoring.

78-84: Characters 78-84 are the seven new characters that Joyce and Lyson (2011) added to Joyce et al.'s (2009) matrix, taken directly from Joyce and Lyson (2011).

Character 85: Maximum adult carapace size greater than $600 \mathrm{~mm}: 0=\mathrm{no} ; 1=$ yes.

Character 86: hyo-hypoplastral callosity, if present, lacks sculpturing on more than 90 percent of its surface: $0=$ no; 1 = yes.

Character 87: xiphiplastral callosity, if present, lacks sculpturing on more than 90 percent of its surface: $0=$ no; 1 = yes.

Character 88: Nuchal sutures to preneural, and/or neural 1, before it sutures to anterolateral edge of costal $1: 0=$ no $1=$ yes. 


\section{APPENDIX 2}

\section{DATA MATRIX}

$a=0 / 1 b=1 / 2 \quad c=2 / 3 d=1 / 2 / 3$

outgroup 00000001000001000000000000000000000000000000100011 $0000000000000000000000010 ? 000000000000$ aubryi 1010300111 1a0b0 1000010021101110311020000 0111- 0101100010 001011010000000000101000000000000 bibroni 2111300300 0a0110011000020001001100010002002001011100111 $1100001011000000000020000000 \mathrm{a} 0000$ cartilaginea 21113002000001102110000001011101000100100010010211 10101000100100100000000002000000010000 elegans 111030041 01a0b $000110000200111102110200000001-0111111000$ 001010111000000000101000000000000 euphraticus 2111301400 010b1 00110000001010001000200100000000221 111020000101101000000000020000 00a10 000 ferox $2111301300012 b 10011001000201000100020000000000022111002$ 000000110100000 0a0a0 $10000001100-0$ formosa $1111300300000100011000120101110100020020000010021100--1$ $0001101---00000000 ? ? ? 000000010000$ frenatum 1000300110 1a0b0 1000010021001110311020001 1021- 01111 10010001011010000000000101000000010000 gangeticus 2110300200 0a1b0 01110000001011101000200200000100111 100020001001010000000000020000 00a10 000 hurum 2110300200 0a1b0 0111000010201110100020020000011021100000 $000100101100000000002000000 a 10000$ indica2121300300 000100011001021001000100010001002002020000111 1100101011000000000020000 00a11 000 leithii 2110300200 0a010 0111000110101110100020020000000021100001 0001001010 ????? ????? ????? ??a10 000 mutica 3111301100 0a2b2 $00111011102010101000200000001-0012211001$ $000000101000000000 \mathrm{a} 01000000110000$ nigricans 2110300200 000b- 01110001001011101000100200020100211 010010001001010 ????? ????? ????? ??a10 000 punctata 1000210111 1b0b0 10000100100011001110200000010100011 00000001010011000000000111000000010000 senegalensis $211031001012-4000000000211010002110200000021-01011$ $00000001011110000000000102000000--0000$ sinensis 3111300100 0b2b1 02111001102011101101200200000200211 10001000000101000000000002000000110000 spinifera $2111301100012 \mathrm{~b} 200111010002010001000200100001-00222$ 11002000000101000000 000a0 1000000110000 steindachneri 1111300300 0a0b0 0211100020201110100120020 0001- 20212 00--1 00000 -1--0 00000000 ?? ?0000 00010000 subplana $31113003000010202111000102011101001210100000-00112$ 10001000100101100000000002000000010000 swinhoei ---1301400 0---- 00110001001010001100200000000000221 11--00001 -1-1 ????? ????? ????? ??--1 000 triunguis 2111300300 010b1 0011000000200110100020100000000011 ? 110010000001010000000000020000 10a10 0-0

thomasii $31 ? 030010$ 11b-c 0??00 00?00 ???01 -01111 21000 00??? ???-2 
VITEK: GIANT SOFT-SHELLED TURTLES

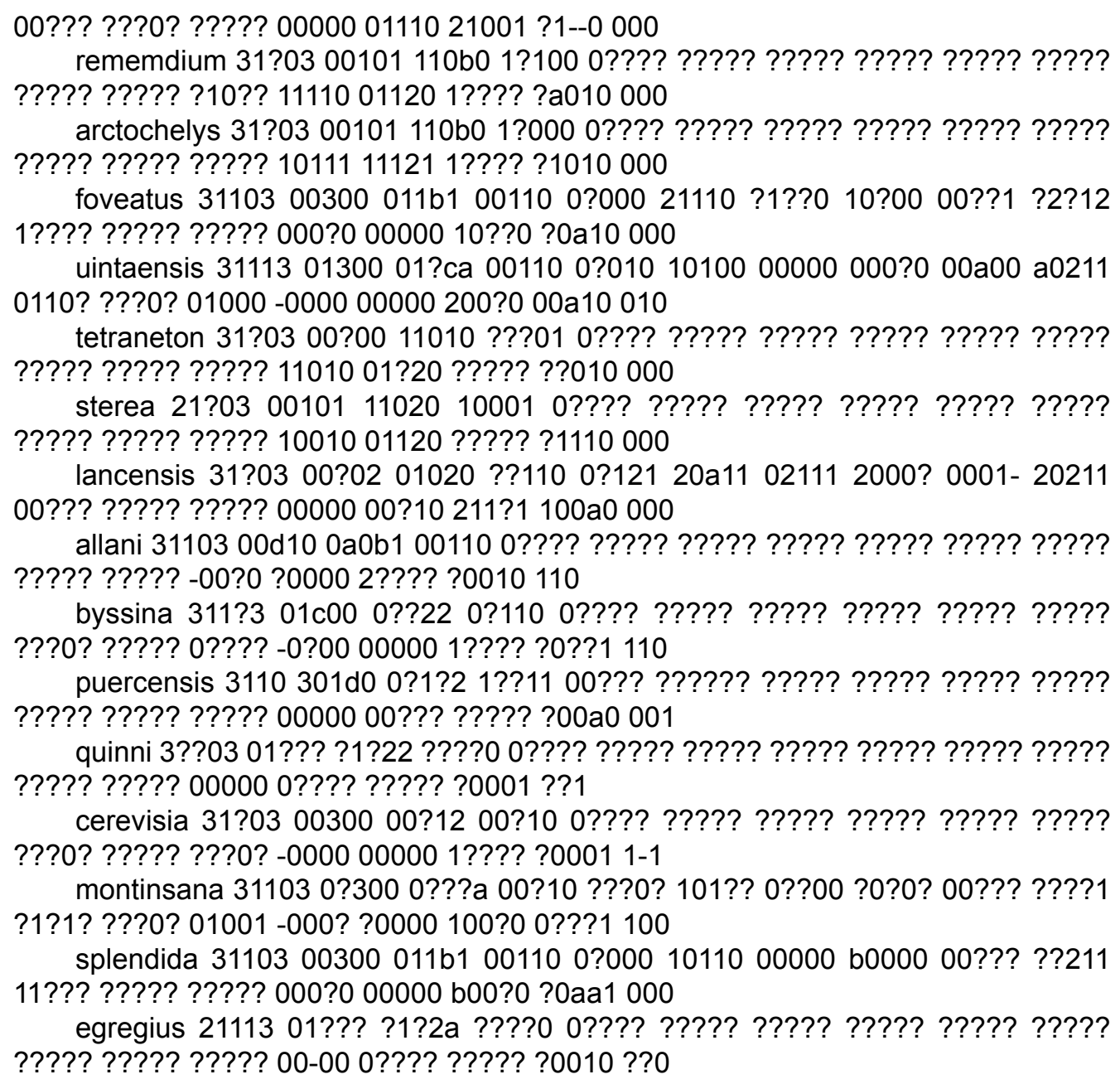




\section{APPENDIX 3}

\section{SPECIMEN LIST}

Apalone ferox: YPM R 10574, skeleton.

Apalone mutica: YPM R 10890, skeleton.

Axestemys byssina: USNM 4089, xiphiplastron, cervical vertebra, isolated ilium, several fragmentary appendicular elements; USNM 12589, skull fragments, partial left dentary, left hyoplastron, right hypoplastron, left and right xiphiplastron; USNM 16174, fragmentary carapace, left and right hyo- and hypoplastra, partial epiplastron; AMNH 1034, partial medial hypoplastron; AMNH 1046, partial medial hypoplastron, partial nuchal, partial costal 1 , costal fragments.

Axestemys cerevisia: UW 2382, a carapace, plastron, partial pectoral and pelvic girdles, and one cervical vertebrae

Axestemys montinsana: UM 27029, a skull, partial lower jaw, partial carapace, fragmentary entoplastron, hyoplastron, and hypoplastron, xiphiplastron, five cervical vertebrae, a partial pelvic girdle, two humeri, a femur, and various disarticulated appendicular elements; PTRM 5350.88, skull fragments; PTRM 5350.23, PTM 5350.24, lower jaw; PTRM 6030.07, PTRM 6030.08, epiplastron; PTRM 6030.01, entoplastron; PTRM 6030.03, hyoplastron; PTRM 6030.04, hypoplastron; PTRM 6030.02, hyo- and hypoplastron; PTRM 6030.05, PTRM 6030.06, xiphiplastron; PTRM 5350.21, PTRM 5350.22, PTRM 5350.30, PTRM 5350.108, cervical vertebra; PTRM 5350.91, PTRM 5350.100, pectoral girdle; PTRM 5350.25, humerus; PTRM 5350.21, pelvic girdle, PTRM 5350.77,5350.78, ilium; PTRM 5350.27, ischium, PTRM 5350.75, PTRM 5350.76, pubis; PTRM 5350.28, PTRM 5350.51, PTRM 5350.130, femur; PTRM 5350.122, tibia; PTRM 5350.47, PTRM 5350.110, PTRM 5350.117, 5350.117, PTRM 5350.121, phalange; PTRM 5350.43, PTRM 5350.105, claw; UCM 49231, skull fragments; UCM 49228, partial dentary; DMNH 44623, costal and plastron fragments; UCM 37755, costal fragments and partial cervical vertebra; DMNH 45130, shell fragments and phalanges; DMNH 44622, plastron fragments and ungual phalanx; DMNH 43187, partial pectoral girdle; UCM 34134, humerus; UCM 34119, phalanx.

Axestemys quinni: FMNH P 26641, carapace.

Axestemys splendida: AMNH 3952, partial carapace; MRF 266, skull; MRF 666, lower jaw; MRF 834-835, partial carapace and complete right hyo- and hypoplastron; MRF 849, partial carapace and dentary; MRF 700, preneural; MRF 631, costal 1; MRF 654, 676, costal; MRF 567, 675, 678 hyoplastron;MRF 699, partial pectoral girdle; MRF 586, MRF 661, femur; TMP 90.50.01, partial skull and skeleton; TMP 2001.12.27, carapace, partial plastron, partial skeleton;

"Trionyx" puercensis: AMNH 1202, partial carapace, partial hyo- and hypoplastron, partial xiphiplastron.

Conchochelys admiribalis: AMNH 6090, skull. 